\title{
Hans Jonitz
}

\section{In amerikanischer und französischer Kriegsgefangenschaft}

In einem Bauernhaus in Holzhausen bei Schweinfurt verbrachte ich die Nacht zum 9. April 1945 im Keller. Wir hörten längst die feindlichen Truppen, als endlich im Morgengrauen ein GI mit MP im Anschlag an der geöffneten Kellertür stand und uns aufforderte, herauszukommen. Der Angstschweiß stand ihm im Gesicht, als nacheinander mehrere graue Gestalten die Treppen emporkamen. Hat er befürchtet, wir würden uns noch wehren wollen? Im Hof traten wir in einer Linie an. Man nahm uns Uhren ab und aus mir unerfindlichen Gründen warf ein GI auch mein Eßbesteck zur Seite mit der Bemerkung: „,Kriegst du alles neu.“ Der alliierte Sieger wußte nicht, was er mir damit angetan hatte. Meine Uhr stieß indessen auf kein Interesse. Einer der beiden Haltebügel für das Armband war abgebrochen, so daß nur noch ein Stück des Lederbandes dranhing.

\section{Die ersten Stationen: Bad Kissingen, Worms, Südfrankreich}

Wir wurden auf Sattelschlepper verladen und nach Bad Kissingen verfrachtet. Im dortigen Kurpark - wie vornehm - verbrachte ich meine erste Nacht hinter Stacheldraht. Dieser war am Rande einer Wiese einfach am Boden um uns gerollt worden. Es gab nichts zu trinken. Dafür erhielten wir die erste feste Nahrung in Form einer Dose weißer Bohnen mit Fleischeinlage. Das war gewiß eine nahrhafte Mahlzeit, aber ohne jedes Getränk genau die falsche. Am nächsten Morgen bestiegen wir erneut einen US-Sattelschlepper. Er war brechend voll. Keiner konnte umfallen. Von Bad Kissingen ging es nach Worms am Rhein, in die dortige PionierKaserne, wo unser Elend erst so richtig beginnen sollte. Trostlosigkeit an allen Ecken und Enden, wohin man auch blickte. Der Kasernenhof war mit hohem Stacheldraht umgeben. An seiner Außenseite verlief die Lagerstraße im Viereck, umrahmt von Kasernengebäuden, die größtenteils ausgebombt waren und als MG-Stände dienten, die auf das Lager gerichtet waren.

Wenigstens 30000 wenn nicht 40000 von Tag zu Tag mehr dahinvegetierender, trauriger Gestalten hausten auf dem blanken Boden des Kasernenhofes. Kein Dach über dem Kopf, dafür jede Menge Regen. Aprilwet- 
ter eben. Nacht für Nacht versuchten wir, in Etappen zu schlafen. Alle auf einmal fanden ohnehin keinen Platz zum Liegen. Wir bildeten eine Dreiergruppe, kratzten am Abend mit Stiefelabsätzen die nasse Oberfläche des Bodens weg, und ich legte meinen Kradmantel (Gummi-Mantel) auf den Boden. Auf diesen legten wir uns zu dritt, um uns mit einem zweiten Kradmantel zuzudecken. Und so froren wir dahin. Jeden Morgen marschierten wir in Sechserreihen in Richtung Feldküchen, die außerhalb auf der Lagerstraße standen, um uns eine Brühe abzuholen, die sich Kaffee nannte. Dazu gab es ein paar, etwa drei bis fünf Wehrmachtskekse, wie sie einst zur Eisernen Ration gehörten. Die Menge hing allein davon ab, wieviel Stück der Verteilende gerade in seine Finger bekam, um sie auszugeben. Weil wir oft von den amerikanischen Wachposten nach dem ,Essenfassen" zur Eile angetrieben wurden und beim Laufschritt der EBgeschirrdeckel überschwappen konnte, tranken wir die Morgengabe sofort. Einmal hat es auch mich beim Essenfassen erwischt, als mir ein regelmäßig sein Gewehr schwingender GI mit voller Wucht in das Kreuz schlug. Das tat im doppelten Sinne weh. Mit einer solchen Behandlung durch meine „Befreier" hatte ich nicht gerechnet. Es gab dann noch täglich eine Suppe aus Wehrmachtsbeständen, worin einige Graupen oder ähnliches schwammen.

Gleich hinter dem Stacheldraht fand der Reichtum statt. Dort gab es Essen in Hülle und Fülle. Beste amerikanische Soldatenverpflegung, an der auch jene Kriegsgefangenen sich beteiligen konnten, die das Glück hatten, als Arbeitskommandos der verschiedensten Art eingeteilt worden zu sein. Für sie war mehr als reichlich, was die Amis übrigließen. Am Abend kamen diese Landser in das Lager zurück und versorgten ihre engsten Freunde noch mit einer Scheibe Weißbrot und vielleicht sogar einer Zigarette. Leider war ich nicht unter den Glücklichen. Dafür war ich mir darüber klar, daß ich hier vor die Hunde gehen konnte. Bei dieser Ernährung kam ich völlig von Kräften. In einer Ecke des eingezäunten Vierecks war eine große Grube geschaufelt worden, umgeben von aufgeschütteter, ausgehobener Erde. Eine Sitzgelegenheit gab es da nicht, aber dieses Loch diente den über 30000 als Toilette. Man mag sich ausdenken, wie penetrant es dort stank; denn auch in unmittelbarer Nähe mußten ja Tag und Nacht irgendwelche Gefangenen aushalten. Einzelne sind nächtens hineingefallen und elend erstickt. Innerhalb des also unvorstellbar primitiven Gefangenenlagers gab es aber ein „Abgangs-Cage“. Es war durch einen Drahtzaun vom übrigen Lager separiert.

Und von dort aus gingen täglich Transporte in Arbeitslager ab. Unter allen Umständen mußte ich da hinein, notfalls illegal und mit Gewalt. Die letzten Tage des April waren angebrochen, als ich es eines Nachts schaffte. Ich robbte mit anderen unter Aufbietung aller noch vorhandenen Kräfte unter dem Maschendrahtzaun hindurch, nachdem wir vorher mit unseren Händen eine kleine, aber ausreichende Bodenvertiefung gekratzt 
hatten. Wie erwartet, wurden wir anderntags zum Abtransport zusammengestellt und zum Bahnhof von Worms gebracht, wo wir einen Güterzug bestiegen. Die Gerüchteküche dampfte. Wo würde es hingehen? Ich taxierte damals mein weiteres Schicksal mit ca. $1 \frac{1}{2}$ bis 2 Jahren Gefangenschaft, gleich an welchem Ort. Entscheidend war, wie im Krieg gelernt und $x$-fach geübt, das Überleben schlechthin bei ausreichender Ernährung. Wenn dazu ein Arbeitseinsatz kam, konnte es nur recht sein. Das verdrängte vielleicht die Trübsal.

In unserem Güterwagen waren wir wenigstens vierzig, wenn nicht mehr Gefangene, die am Boden herumsaßen oder standen. Irgendwelche Liegepritschen gab es nicht. Vor der Abfahrt wurden uns noch amerikanische Konserven und, für alle zusammen, ein Kanister Wasser gereicht. Die Konserven bestanden aus drei Päckchen pro Kopf, die jeweils ein Frühstück, ein Mittag- und ein Abendessen enthielten. Kekse, Marmelade und vier Zigaretten im Frühstücksteil waren das erste, wonach ich griff. Ferner waren zugeteilt Dosen mit Bohnen, Erbsen, Fleisch usw. Leider gab es Landser, die den Inhalt des Empfangenen gierigst verschlangen und im weiteren Verlauf des Transportes, der einige Tage dauern sollte, krank wurden. Keiner konnte ihnen helfen. Die Luft wurde immer dicker, und es stank entsprechend. Unsere Lage wurde um so schlimmer, als das Trinkwasser bei weitem nicht reichte. Wir wußten ja nicht, auf wie viele Tage wir es zu verteilen hatten.

Zu den positiven Eindrücken auf jener Reise ins Ungewisse zählt die Betrachtung der lieblichen pfälzischen Landschaft durch das Fenster am oberen Ende des Güterwagens. Die Obstbäume standen in voller Blüte. Es war ein lange nicht gekanntes Bild des Friedens. Die Sonne schien jetzt, und es wurde nicht mehr geschossen. Es war unser Glück, daß unser Waggonfenster vergittert war. Auf der Fahrt durch Frankreich, denn dahin ging es, wurden wir auf jedem Bahnhof, ja bei jedem Halt, von haßerfüllten Franzosen mit Steinen oder Kohlestücken beworfen. Unsere farbigen amerikanischen Wachposten mußten uns vor ihren Alliierten in Schutz nehmen und die Angreifer mit in die Luft gerichteten MP-Salven vertreiben. Je länger die Fahrt dauerte, um so größer wurde die Tortur. Die Türen wurden nicht geöffnet. Wir wurden immer apathischer. Die hygienischen Verhältnisse mag sich der Leser dieses Erlebnisberichtes selbst ausmalen ...

Wo unser Transport seinen Zielbahnhof erreichte, weiß ich heute nicht mehr exakt. Vermutlich war es der Bahnhof von Séptème, wo wir 1946 wieder einsteigen sollten. Ein langer Marsch brachte uns in das Lager mit der Bezeichnung POWE 404, welches einige hunderttausend Landser in schrecklicher Erinnerung behalten sollten. Dieses gigantische Lager, angelegt mitten in einer dürren südfranzösischen, einigermaßen flachen Gegend unweit von Marseille, war in etwa 25 Cages aufgeteilt. Eine ganze Reihe davon sollte ich in den nächsten Wochen kennenlernen; denn wir 
wurden aus Gründen, die wir nicht verstanden, mehrmals verlegt. Uns auferlegte Schikane gab es aber überall. Wir zogen ein und lagen auch hier für einige Wochen in Gottes freier Natur am Boden, kein Dach über dem Kopf. Fast ein Jahr später haben wir, jeder einzelne, auf unserem „Entlassungs-Papier" per Unterschrift anerkannt, stets über dem Boden geschlafen zu haben.

Unser erster Komfort bestand darin, leere US-Kartons zu organisieren, die wir ausbreiteten, um darauf zu liegen. Irgendwann kam ich in ein Cage, wo wir niedrige US-Ein-Mann-Zelte vorfanden. Darin lagen wir zu dritt, wiederum auf Kartons, versteht sich. In jene Zeit fiel eine bedenkliche Verschlechterung meines Gesundheitszustandes. An Verpflegung erhielten wir ein Minimum zum Leben. Morgens um 5 Uhr war Wecken, anschließend Fahnenappell und Zählen aller Anwesenden. Dies taten amerikanische Soldaten, begleitet vom deutschen Lagerführer und jugoslawischen Hilfstruppen, die wir „Jabos“ nannten, weil sie immer unverhofft auftauchten, wie Jagdbomber im Krieg. Dann setzte sich ein Heer von Tausenden in Marsch, um den Morgenkaffee zu fassen. Es gab dazu pro zehn Mann ein amerikanisches Weißbrot, was pro Kopf gerade eine Scheibe bedeutete. Wir waren so ausgehungert, da $\beta$ tatsächlich Buch geführt wurde, in Form einer Kladde, wie wir sie von Schießübungen her kannten. Das Ganze hatte den Zweck, gerecht festzuhalten, wer eines der beiden Brotenden erhielt. Darauf war ja länger zu kauen als auf einer Scheibe. Am Tage gab es eine Suppe. Anders kann ich das warme Essen nicht bezeichnen, denn zu einem Eintopf fehlte die nötige Dicke. Auch eine süße Speise wurde uns, je nach Speiseplan, gereicht. In der dünnen Brühe, aus Trockenmilch angerührt, schwammen, wenn man Glück hatte, einige Pflaumen oder Rosinen. Es war hier, wie beim Suppenfassen, von größter Bedeutung, so spät beim Essenausgeber vorbeizukommen, daß dieser die restlichen Essenschläge mit seiner Kelle aus der Tiefe des Kessels holte. Wer hier dabei war, konnte sich satt essen.

Je länger ich in diesem Lager weilte, um so seltener konnte ich nur noch die Toilette aufsuchen. In der Woche einmal war schließlich schon viel. Ich entschloß mich deshalb, mich zum Sanitätszelt zu begeben, um eventuell ein Abführmittel zu erhalten. Zuerst durfte ich hier, zusammen mit anderen Kranken, nach längerem Warten eine knappe Stunde exerzieren und dabei das Lied singen: „Ich weiß nicht, was soll es bedeuten." Ich erhielt aber schließlich von einem Sanitäter ein Abführmittel, das ich sofort einnahm, wahrscheinlich in zu großer Menge. Ich kann die Qualen nicht schildern, die mich in der folgenden Nacht überfielen. Stundenlang saß ich unter heftigsten Schmerzen auf dem „Donnerbalken“; denn, was sich hier angesammelt hatte, saß steinhart am Ende des Darmes. Schließlich habe ich das Darmende mit den Fingern aufgebrochen. Den Rest der Nacht und auch den folgenden Tag lag ich total erschöpft am Boden. Doch es hieß wieder einmal: umziehen. Im neuen Cage bekamen wir ein 
richtiges Dach über den Kopf. Es handelte sich um ein sogenanntes „Hauszelt". Ein solches Zelt dient normalerweise zwei US-Soldaten. Man konnte zwei Feldbetten an den Längsseiten des Zeltes aufstellen. Wir schliefen zwar auch hier weiterhin auf der Erde bzw. auf Pappkarton, teilten aber das Zelt unter zwanzig Gefangenen. Auf jeder Seite waren zehn Mann hingeschlichtet, mit den Füßen Richtung Zeltmitte, die meist in Achselhöhe des Gegenüberliegenden steckten. Umdrehen konnten wir uns, wenn es keinen nächtlichen Streit geben sollte, eben nur gemeinsam. Für uns Zeltbewohner gab es nun tagsüber eine ganz besondere Schikane. Am Mittelmeer herrschten inzwischen ja längst sommerliche Temperaturen. Schließlich schildere ich jetzt die Wochen von Mai und Juni 1945. Wir durften hier während des ganzen Tages das Zelt nicht betreten, um dort Schatten zu finden. Lediglich das Eßgeschirr konnte zu bestimmter Zeit geholt werden. Wir hatten inzwischen Decken bekommen, die wir, einige tausend Mann, nach US-Vorschrift einheitlich zusammenlegen mußten. Die Decke wurde am Kopfende des Liegeplatzes abgelegt, auf jeder Zeltseite also zehn Stück, obenauf das Eßgeschirr. Das war aber nicht alles. Sowohl innerhalb des Zeltes als auch von Zeltstraße zu Zeltstraße, von einem Stacheldraht bis zum anderen des gesamten Cages, mußten täglich morgens die Decken mittels einer langen Schnur ausgerichtet werden. Schließlich hatte jede Zeltgemeinschaft ein Stück Karton mit irgendwelchen Einschnitten versehen. Auf diese Weise konnte und mußte vor dem Verlassen des Zeltes auf dem Sandboden zwischen den aufgelegten Dekken ein Muster in den Sand gedrückt werden. So konnte man an den Fußspuren sofort erkennen, ob jemand unerlaubt das Zelt betreten hatte. Wenn wir nicht aufgerufen waren, uns zur Einteilung von Arbeitskommandos zu versammeln, wurde marschiert. Immer im Viereck und von Essenspause zu Essenspause. Einmal sangen wir auf Anweisung immer nur das Lied „Oh, du schöner Westerwald“. Wir sangen auch, wenn der Sandsturm blies, also mit knirschenden Zähnen.

$\mathrm{Zu}$ den lichten Momenten in unserem Elend zählte aber ein wirklich schöner Gesang, vorgetragen durch den Lagerchor, der sich hier in Eigeninitiative gebildet hatte. Es waren beschauliche, abendliche Minuten, trotz unserer Trübsal, wenn bei untergehender Sonne alte deutsche Volksweisen erklangen. Der Chorleiter hielt auch improvisierte Vorträge über Musikgeschichte. Auf mich machte er den Eindruck eines Musikprofessors. Er stammte vom Niederrhein, ich glaube aus Erkelenz. Wir hatten inzwischen nämlich fast alle die Namen unserer Heimatorte mit Faden oder Schnur seitlich auf unsere Mütze gestickt, so daß jeder sofort wußte, ob er einen engeren Landsmann vor sich hatte. Das durfte ich eines Tages besonders eindrucksvoll erleben. Bei einem abendlichen Bummel von einem Lagerstraßenende zum anderen sah ich plötzlich im Nachbarcage meinen Vetter Georg. Er war magenkrank und lag mit anderen Kranken in einem separaten Viertel in unmittelbarer Drahtzaunnähe. Mein Vetter war Nicht- 
raucher. Weil er aber magenkrank war, erhielt er, welche Ironie, eine Tabakzuteilung, während wir Zehntausende von Landsern automatisch wenigstens vorübergehend Nichtraucher und Nichttrinker waren. Georg warf sein Paket „Prince Albert"-Tabak über den Drahtzaun, und von einer Sekunde zur anderen war ich in meinem Cage ein König. Plötzlich kamen nicht nur alle, die von diesem Ereignis hörten und aus Nürnberg und Umgebung stammten, sondern es waren sogar welche dabei, die noch über Zigarettenpapier verfügten. Reichlich schnell war auf diese Weise der Tabak alle, und die Landsleute verkrochen sich wieder in ihre Ecken.

Ich habe noch nicht erklärt, wie ich wieder zu Messer und Löffel kam. „Kriegst du alles neu“, hatte ja der GI am 9. April gemeint. Zwar konnte ich, was uns bisher, außer Brot, an Nahrung geboten wurde, getrost auch trinken. Aber Messer und Löffel waren schon etwas Feines, und ich ging deshalb folgendermaßen vor: Ich organisierte mir, wie viele andere, ein ca. $15 \mathrm{~cm}$ langes Stahlblechband, mit welchem US-Verpflegungskartons umspannt waren. Etwa die Hälfte davon umwickelte ich ganz eng mit einer Schnur. Das war der Griff. Das restliche Stück wurde mit unendlicher Geduld auf einem Stein so lange geschliffen, bis man einigermaßen damit schneiden konnte. Nun opferte ich mein Kochgeschirr. Das konnte ich mir leisten, denn inzwischen hatte ich einen „Invasionseimer", d.h. eine leere, große US-Dose, organisiert, die zum Essenfassen ausreichte. Mit dem ,Messer“ schnitt ich in einem langwierigen Prozeß ca. $2 \mathrm{~cm}$ in die Oberkante des Kochgeschirrs. Dieser Behälter war aus Aluminium, also einem relativ weichen Material. Im weiteren Verlauf nahm ich meine beiden Hände zu Hilfe und alle Kraft zusammen, um das Kochgeschirr buchstäblich von oben nach unten aufzureißen. Nun legte ich einen Teil des Geschirrmaterials, welches ausreichend groß war, um einen Eßlöffel daraus zu fertigen, auf einen Stein und schlug das Aluminium mit einem weiteren Stein platt. Für den nächsten Arbeitsgang brauchte ich einen Nagel. Auch dieser war zu organisieren. Ich schlug nun ein Loch neben das andere, auf diese Weise die Konturen eines Eßlöffels schaffend. Diese Perforation versetzte mich in die Lage, den Löffel schließlich mit den Fingern herauszubrechen. Es dauerte wiederum Stunden und Tage in den wenigen Pausen, die uns verblieben, bis ich mit dem eingangs erwähnten Messer alle Perforationsspitzen weggeschnippelt hatte. Aus dem flachen Stück Aluminium aber nun einen richtigen Löffel zu machen, dazu bedurfte es eines besonderen Hammers. Ich ging auf gut Glück zu den wohlhabenden Gefangenen des Stammpersonals, die außer besserem Essen noch vieles andere hatten. Und siehe da, man verfügte über einen Hammer mit einem runden Ende, mit dem ich die Wölbung zuwege brachte. Der Löffel war fertig, wenn auch an seiner engsten Griffstelle reichlich labil. Nachdem ich später ordentliches US-Besteck hatte, warf ich den selbst erzeugten Löffel weg, leider.

Tag für Tag wurden Landser zu Arbeitskommandos eingeteilt und gin- 
gen besseren Zeiten entgegen. Wir Zurückbleibenden wurden weiterhin, selbst beim Essenfassen, gedrillt. Wer nicht eine exakt ausgerichtete Marschordnung einhielt, mit dem Kopf oder Körper also aus der Reihe tanzte, bekam kein Essen. Lagerpolizei überwachte das Ganze bei der Essensausgabestelle. Nicht die Amerikaner haben uns nach meiner Beobachtung angerührt. Aber sie duldeten sowohl Ungerechtigkeiten der von ihnen eingesetzten Lagerführer, wie sie sich auch ihrer jugoslawischen Wachmannschaften im Lager bedienten. (Auf den Wachtürmen standen übrigens ständig farbige US-Soldaten.) Einer dieser „Jabos“ hieb mir eines Tages beim Appell seine mehrschwänzige Peitsche über die Brust, weil ich ihm zu weit vor der Front stand. Die deutschen Lagerführer hatten eine ungeheure Macht. Sie trugen auch ungeniert ihren Reichtum zur Schau und protzten mit Uhren, Ringen und Kettchen. Vielen von ihnen sollte es dafür Monate später recht dreckig gehen.

Inzwischen war auch der Krieg zu Ende. Am Abend des 8. Mai transportierte ich gerade eine Schubkarre voll Steine, als ich von weither den Ruf vernahm: „Der Krieg ist aus.“ Nach getaner Arbeit versammelte ich mich mit anderen, denen danach zumute war, zu einem Dankgottesdienst. Wir bildeten einen großen Kreis, in dessen Mitte der Lagerpfarrer sprach, und endeten mit dem Choral: ,Nun danket alle Gott.“ Und während des gesamten Gottesdienstes umkreisten uns die ,Jabos“.

\section{Juni 1945: Arbeitslager 416}

Eines heißen Tages - es war inzwischen Ende Juni geworden, und wir lagen inzwischen fast ein Vierteljahr unter Frankreichs heißer Sonne - hatte ich endlich Glück. Zu keiner Zeit war mein Beruf als kaufmännischer Angestellter gefragt. Handwerker, Eisenbahner, Landwirte, Köche usw. waren bevorzugt. Alle Arbeitskompanien trugen phantasievolle Namen. Unsere soeben aus dem Nichts entstandene Kompanie erhielt den Namen „Nachtigall“. Wir klaubten unsere spärlichen Klamotten zusammen und bestiegen wieder einmal einen US-Sattelschlepper. Latrinengerüchte sahen uns bereits auf dem Weg in ein Arbeitslager nach Deutschland. Indessen hielten die Fahrzeuge schon nach wenigen Kilometern. Unsere neue Heimat sollte das Lager mit der Adresse „8540 Labor Service Co 416 POWE 5th Labor Supervision Area APO 772“" sein. Im allgemeinen Sprachgebrauch war dies das Arbeitslager 416. Wir konnten von hier aus sogar noch hinübersehen zum Lager 404. Die Gegend war flach und übersichtlich. Wer je im Lager 404 leiden mußte, wird das nie im Leben vergessen können. Unsere Gedanken schweiften noch einmal hinüber. Wir hatten das Gefühl, an einem Wendepunkt angelangt zu sein. Drei Monate lang waren Hunger und Demütigung unsere Wegbegleiter. Warum nur hatte man uns lediglich Verpflegung für ein Existenzminimum gegeben? 
Glaubte man, uns nur auf diese Weise arbeitswillig zu erhalten? Meinte man, wir würden - waren wir erst einmal gut gefüttert - nur noch faul herumliegen wollen? Verkannte man uns Deutsche so sehr? War es nötig, daß man von vereinzelt anzutreffenden ehemaligen $\mathrm{KZ}-\mathrm{Häftlingen,} \mathrm{die} \mathrm{in}$ den dreißiger Jahren vorübergehend eingesessen hatten, aber dann Soldaten wurden, das Wort hörte: „Das ist hier ja schlimmer als im (Vorkriegs-)KZ!"“

Nicht die Frauen waren, wie sonst unter Landsern üblich, das „Thema 1", sondern Essensrezepte. Was wurde da nicht alles von Landsmannschaft zu Landsmannschaft an Spezialitäten ausgetauscht. Und wer träumte nicht alles davon, gleich nach der Heimkehr diese Rezepte in der eigenen Küche zu realisieren. Dabei waren wir ohne jede Nachricht von zu Hause. Dieser Zustand verstärkte unser Elend. Seit fast vier Monaten wußte ich nicht, ob und wie Irmgard und meine Familie das Kriegsende überlebt hatten. In meiner seelischen Not war mir in jenen Wochen ein Büchlein sehr hilfreich. Ich besaß ein kleines Reclam-Heftchen, welches ich, einmal gefaltet, in meiner Brusttasche trug. Sein Inhalt: „Hermann und Dorothea" von Goethe. Diese zarte Geschichte eines Flüchtlingsschicksals in der Mitte des vorigen Jahrhunderts paßte so richtig in die jetzige, unruhige Zeit. Ich las sie wenigstens ein halbes dutzendmal. Und nun sollte mich Goethe auch in das Arbeitslager begleiten. Inzwischen waren aus der kleinen Geschichte fliegende Blätter geworden.

Wir sahen zu unserem Empfang nicht nur einen wohlgenährten Lagerführer, das wäre etwas durchaus Übliches gewesen. Nachdem er uns zu Disziplin, Ordnung und Kameradschaft aufgerufen hatte, stellten wir fest, daß im Hintergrund nur gut genährte Gestalten herumliefen. Glaubten wir zunächst, das sei ja auch nur das ,Stammpersonal“, so merkten wir doch bald, daß hier völlig andere Verhältnisse herrschten als in 404.

Die Kompanie ,,Nachtigall“ wurde auf große Ein-Mast-Zelte aufgeteilt. Das war nun schon etwas ganz anderes. Auch hier waren wir jeweils zwanzig Insassen, aber wir konnten uns aufrecht bewegen. Es war entschieden geräumiger als unsere alte Zeltunterkunft. Weiterhin war unsere Lagerstatt der Boden Frankreichs, belegt mit US-Kartons. Und wenn es im Mittelmeerraum einmal regnete, konnte es passieren, daß das Wasser am Boden in die Zelte rann und aufweichte, was wir nicht rechtzeitig in Sicherheit brachten.

Alle hier eingesetzten Gefangenen waren irgendwie für die US-Truppen tätig. Es gab Arbeitskommandos wie: Küchen-Personal, Verpflegungslager, Müll-Kommando, Küchenabfall-Fahrer, Papiersammler, PX-Clubarbeiter, Straßenreiniger, Bauarbeiter jeder Sparte, Motor-Pool-Spezialisten usw. usw. Das Küchenpersonal blieb ganztags außerhalb des Lagers und mußte morgens vor allen anderen Kommandos bereits um 5 Uhr abrükken. Nach 14 Stunden kamen sie als letzte um 19 Uhr zurück. Alle anderen Arbeitskommandos begannen um 7 Uhr und hatten Mittagspause und 
Verpflegung im Lager. Nach meiner Erinnerung setzten unsere Lagerköche, als wir dort eintrafen, täglich etwa zwanzig große Kessel auf. Morgens gab es Kaffee und Brot, mittags und abends einen erstklassigen Eintopf, gemessen an all dem, was wir hinter uns hatten. Und täglich erscholl der Aufruf ,Nachschlag“. Wer wollte, konnte also, solange der Vorrat reichte, ein zweites Mal Essen fassen. Doch merkwürdig. Obwohl doch nur das Kochpersonal an die US-Küchen angeschlossen war, wurde im Lager im Laufe der Monate immer weniger gekocht. Im Winter 1945 standen allenfalls noch acht bis zehn Kessel ausgabebereit. Die Auflösung dieses Rätsels: Immer mehr Arbeitskommandos schlossen sich unerlaubt bei der Essensausgabe den US-Soldaten an, sobald diese gefaßt hatten. Es war ja genug da. Die Mittagspause diente somit nur noch der Ruhe.

Meine erste Arbeit galt dem Einsammeln von Abfällen in einem großen Freilicht-Kino. Das war nicht nur Papier usw., sondern darunter waren natürlich auch Zigarettenkippen und vereinzelt sogar ganze Glimmstengel, die versehentlich verlorengingen. Wir sammelten zuerst das Rauchbare und dann die übrigen Abfälle. Zeit genug war ja vorhanden. So wurde ich nach langen Wochen wieder Raucher, auch wenn es mir nach der langen Entwöhnung schlecht wurde. Dies um so mehr, als der US-Tabak mit seinem süßlichen Geschmack ungewohnt war, von meinem kurzzeitigen ,Prince Albert"-Erlebnis einmal abgesehen. Allerdings muß gesagt werden, daß fernerhin unsere monatliche Tabakration nach meiner Erinnerung zehn Päckchen betrug. Das Kippensammeln erübrigte sich also bald. Originale Zigaretten, die wir „Aktive“ nannten, erhielten wir hingegen offiziell zu keiner Zeit. Wir fanden Wege, uns solche zu organisieren. Nicht allzulang war ich Papiersammler, da wurde ich plötzlich zum Latrinenkommando eingeteilt. Ein ,,anrüchiger" Beruf zwar, aber mit wenig Arbeitsaufwand verbunden. Wir waren ein Zwei-Mann-Kommando und hatten morgens und am Nachmittag jeweils einen Kanister voll Desinfektionsmittel durch die angebaute Spritze in die US-Latrinen zu spritzen. Wir trugen diesen Kanister, der von einem Mann bequem an zwei Schulterriemen rücklings zu tragen war, jedoch zu zweit, indem wir eine Stange durch den Griff zogen, der sich auf dem Kanisterdeckel befand. In längstens zwei Stunden, von Latrine zu Latrine marschierend, war unser Kanister leer. Den Rest des Vor- oder Nachmittags legten wir uns in den Schatten und warteten auf den uns abholenden Jeep, der uns wieder ins Lager brachte. Den Vormittagsdienst beendeten wir hingegen nicht, ohne uns vorher bei irgendeiner US-Küche zu ernähren.

Dieser schlaue Job sollte unsere Tage nicht sehr lange ausfüllen. Ich kam zum Trash-Kommando. Das bedeutete schweren körperlichen Einsatz. Zur Organisation des gigantischen amerikanischen Heerlagers ist zu sagen, daß zur Versorgung aller Soldaten mindestens weit über hundert Küchen dienten. $\mathrm{Zu}$ jeder Küche gehörte am Straßenrand der Abfallbereich. Auf einem Sockel standen sechs ausgediente 200-Liter-Benzinfässer, 
die, an einer Seite geöffnet, zu Abfalltonnen umfunktioniert waren. Daneben standen noch zwei große Zinkblech-Behälter der US-Army, die für die Aufnahme des flüssigen Küchenabfalls, Speisereste usw., diente.

Es gab also einige tausend Abfalltonnen, die von zahlreichen TrashKommandos per Sattelschlepper geleert wurden, und zwar zweimal täglich. Am Anfang fehlte uns schier die Kraft, jeweils zu zweit eine volle Abfalltonne bis in die Nähe der Oberkante eines Sattelschlepperaufbaus zu stemmen, wo zwei andere Gefangene den Inhalt leerten. Und auf einem Sattelschlepper war viel, viel Platz. Nach dem Frühstück und nach dem Mittagessen der Amerikaner waren wir auf Achse. Natürlich fanden wir unter dem Weggeworfenen so manches, was wir selbst noch gut brauchen konnten. Man muß wissen, daß die US-Soldaten gar manches Beutegut oder von Deutschen Geschenktes mit nach Marseille brachten, wo sie plötzlich feststellen mußten, daß sie nichts weiter als den US-Inhalt ihres US-Seesackes mit an Bord nehmen durften. Alles andere wanderte in den Abfall. Trashfahrer wurden wegen ihrer ständigen Suche nach Verwertbarem auch ,Tonnentaucher" genannt. Tag für Tag brachten wir zwei Sattelschlepperfuhren randvoll auf die Deponie zum Verbrennen. An die viele Arbeit hatten wir uns gewöhnt. Wir waren eine kameradschaftliche Gruppe, und der den farbigen Sattelschlepperfahrer begleitende US-Sergeant war uns wohl gewogen. Trotz Fraternisierungsverbot ließ er mit sich diskutieren. Gar manches Mal fanden wir morgens bei Arbeitsbeginn ein paar eingewickelte Bonbons auf der Ladefläche. Das war zwar nur eine Geste, aber es sind die Kleinigkeiten, die Freude machen und fröhlich stimmen. Beim Tonnentauchen hatte ich Feinseife, Rasierseife, einen aus Deutschland mitgebrachten seidenen Schlafanzug, Rasierwasser, ein Taschenmesser (verboten) gefunden und noch manches mehr. Ich war also wohlhabend geworden. Aber meine Tätigkeit ging wieder einmal plötzlich zu Ende. Ich wurde für eine US-amerikanische Küche eingeteilt. Wie alle Küchenkommandos bestand unsere Kochgruppe aus 15 Mann, von denen jeweils zwei dienstfrei hatten. Zu jedem Küchenbereich zählten mehrere Reihen von Drei-Mast-Zelten zur Aufnahme von im Normalfall bis zu 800 US-Soldaten. Die dazu nötige Verpflegung faßten wir in einem Verteilerdepot, dem eine bestimmte Anzahl Küchen angeschlossen war. Die Depots faßten ihre Vorräte im Hauptlager. Man macht sich keine Vorstellung von der Größe dieser Verpflegungszentrale. Haushoch und Hunderte von Metern lang in mehreren Reihen waren die Kartons und Kisten gestapelt. Schließlich muß bemerkt werden, daß Marseille 1944 der erste französische Hafen war, der intakt für die Versorgung der US-Armeen verwandt werden konnte. Als der Krieg plötzlich zu Ende war, lagerten riesige Vorräte, und die Truppen zogen ihrerseits, ein Schiff nach dem anderen, wieder aus Europa ab. Zumindest auf dem Verpflegungssektor gewannen wir einen Eindruck von der überragenden Organisation in der US-Army. Der Papierkram überwog den des deutschen Militärs bei weitem. Aber dem Es- 
sensfahrplan konnte man zum Beispiel am 10. Juli entnehmen, was es am 11. November zum Mittagessen geben würde. Und das stimmte. So minutiös wurde hier geplant. Tag für Tag gab es das seit langem Vorgedruckte. Die Depots waren entsprechend sortiert, und die deutschen Gefangenen spurten. Ob Hauptlager, Verteiler-Depot, Küche, Trash-Kommando, Motor-Pool oder welches Kommando auch immer, überall waren die Gefangenen selbst die Ausübenden. Die Amerikaner kümmerte das nicht weiter. Hauptsache, der Laden lief. So hätten z. B. in jeder Küche wenigstens zwei US-Soldaten der jeweils durchzuschleusenden Einheit Dienst tun müssen. In der Praxis war das aber nicht der Fall. Wir ließen uns täglich um 5 Uhr morgens in einem Lkw abholen. Wir sagten einfach bei jedem nach Tagen oder Wochen stattfindenden Einheitswechsel, daß die Abholung per Auto üblich sei. Es waren ja eh genug da. Eigentlich hätten wir laufen müssen und auch keinen abholenden Posten mehr gebraucht.

In meiner Kochgruppe zählte ich nicht zu jenen, die das Essen zuzubereiten hatten. Das taten Fachkundigere, darunter auch zwei Bäcker. Meine regelmäßige tägliche Arbeit bestand aus

1. Konserven öffnen und den Inhalt in Töpfe leeren.

2. Leere Konservendosen (Hunderte!) mittels Holzstampfer pressen. Sie durften nur in diesem Zustand in die Tonnen geworfen werden.

3. Tägliche Ausgabe von Milch und Zucker beim Kaffee- oder Tee-Empfang.

4. Täglich zweimal Reinigen der sechs Abfalltonnen und der zwei Lebensmittelbehälter.

5. Hilfe beim abendlichen Küchensäubern.

All dies klingt recht einfach. Es war aber eine Menge Arbeit. Auf der anderen Seite waren wir jetzt, an der Quelle stehend, die Bestverpflegten in der ganzen Area. Und wenn es schon mal Frischeier gab statt Trockenei, dann wanderten die ersten Exemplare schon gleich nach $5 \mathrm{Uhr}$ in unser Eßgefäß. Wir machten uns Kraftbrühe mit Ei. Weil es dann für Spiegeleier nicht mehr reichte, die Eier waren ja abgezählt, gab es eben Rührei. Die GIs waren auch so zufrieden, denn Frischeier waren eine Rarität.

Gegen gute Zigaretten waren wir vielen US-Soldaten beim Wäschewaschen behilflich. Damit war keine besondere Anstrengung verbunden. Waschbürsten brauchten wir dazu nicht. Die Amis hatten zur Reinigung ihrer Eßgeschirre vor jeder Küche drei Tonnen stehen, die mit Wasser gefüllt waren, welches mit benzinbetriebenen Einsätzen erhitzt wurde. Zwischen den Mahlzeiten benützten wir den ersten Bottich, der üblicherweise für die Grobspülung diente, hängten eine mit Löchern versehene Dreiliterdose, zur Hälfte gefüllt mit Kernseifewürfeln, in das kochende Wasser und fabrizierten damit eine hervorragende Seifenlauge. Dann ließen wir die Wäsche kochen.

Wir zogen die Wäsche auch noch durch klares Wasser und wrangen sie aus. Je nach Wäscheumfang brachte diese Arbeit vier bis sechs Packungen 
US-Zigaretten. Für das Trocknen wollten wir keine Verantwortung übernehmen. Wir überließen es den Soldaten, dafür selbst zu sorgen. Denn die Papiersammler, mittlerweile perfekt mit nagelbewehrten Stecken ausgerüstet, liefen durch alle Zeltreihen und wechselten, wenn sie sich nicht beobachtet fühlten, schon einmal ihre schmutzige Wäsche gegen frisch gewaschene. Das war kein Diebstahl, sondern nur bequemer Tausch. Kommando „Von der Leine“ hießen diese Landser. Es gab aber auch noch ein "Kaufhaus Rothschild ohne Schaufenster". Damit war das Bekleidungskommando gemeint. Die US-Soldaten wurden, sobald sie nach Hause fuhren, neu eingekleidet und gaben ihre alten Klamotten ab. Zwei Mann unserer Zeltgemeinschaft waren dort tätig. Für uns bedeutete das, daß wir unsere eigenen Drilliche einfach gegen neue wechselten. Unsere Freunde rückten eben abends mit zwei Drillichen am Leib ins Lager ein.

Mit den ständig wechselnden US-Truppen kamen wir in der Regel gut zurecht. Einige Beobachtungen blieben mir in Erinnerung. Nach Kriegsende erfolgte die Entlassung aus der US-Army nach einem Punktsystem. Es gab für alles mögliche Punkte. Für Gesamtdienstzeit, Übersee-Tätigkeit, Feindeinsatz, Auszeichnungen, Verwundungen usw. „High-Pointer“ waren jene GI, die uns am sympathischsten schienen. Das waren Frontsoldaten mit Erfahrung, die spontan für uns Verständnis hatten und fürsorglich eingestellt waren. So stellte eines Tages ein US-Feldwebel in der Mess-Hall unweit der Türe einen Karton auf den Tisch und malte darauf: "Smoking for the PW" (Prisoner of war). Wir bekamen von dieser Truppe Zigaretten und Tabak in Hülle und Fülle. Je später aber die Truppen in Marseille eintrafen, etwa Ende 1945, um so distanzierter gaben sie sich. Manche meinten, ob wir nicht von der SS wären, weil wir immer noch Gefangenendienst täten.

Die US-Soldaten waren auch geduldig wie die Lämmer. Für alles, ob es klappte oder nicht, hatten sie ihr ,o.k.“. Es gab nichts, wo sie nicht Schlange standen. So auch vor der Küche. Ehe die Offiziersmessen eingerichtet waren, beobachtete ich mit großem Respekt, daß die US-Army keine Rangunterschiede kennt, wenn es ums Essen geht. Da war eben der Hungrigste der erste vor der noch geschlossenen Türe. Und wenn dies ein Feldwebel war, so konnte hinter ihm ein Major und dann ein Gefreiter stehen. Das hat mir imponiert. Beim deutschen Barras undenkbar. Und jeder bekam, was ihm zustand. Wollte ein GI ein zweites Stück Kuchen, so hatten wir als Gefangene Auftrag, ihm zu sagen, er möge wiederkommen, wenn alle gefaßt hatten. Auch das war ,o.k.".

Einmal mußte ich befürchten, mir unfreiwillig den Unwillen vieler Soldaten zugezogen zu haben. Es war beim Morgenkaffee. Ich hatte ständig etwa ein Dutzend geöffnete Kondensmilchdosen und ein großes, rundes Blech vor mir stehen, auf welches der Inhalt eines 10-Pfund-Zuckersackes geleert war. Jedermann bekam Milch und Zucker nach Bedarf. Als an jenem Tag der Zucker zur Neige ging, griff ich zum nächsten Sack und 
schüttete den Inhalt auf den übriggebliebenen Zuckerrest. Eine ganze Reihe Soldaten hatte bereits Kaffee gefaßt und war in die Mess-Hall entschwunden. Da kamen die ersten spuckend zurück. Ich hatte versehentlich den Salzsack erwischt und den Kaffee fleißig gesalzen. Nicht einer ist deswegen ärgerlich geworden. Der Schaden wurde behoben.

Und noch ein Eindruck: Eines Tages gerieten sich ein Offizier und ein Feldwebel mächtig in die Haare. In ihrer Rage zogen sie ihre Uniformjakken aus und begannen eine Keilerei. Anschließend zogen sie sich wieder an und gingen. Man sagte mir später auf Befragen, daß die beiden normale US-Bürger wären, solange sie ihre Uniform mit Rangabzeichen nicht trügen. Als Bürger konnten sie raufen. Ein Mitglied unserer Kochgruppe wurde von uns selbst teilweise vom Dienst freigestellt, um Glasherzen zu basteln. Damit war bei den Amerikanern ein Geschäft zu machen. Gegen Rauchwaren natürlich. Die Herzen schnitten wir in einer Abmessung von $2 \times 2 \mathrm{~cm}$ aus Plexiglasscheiben von ca. $4 \mathrm{~mm}$ Dicke. Mühevoll wurden sie mit dem Messer herzförmig zugeschnitzt. War dies geschehen, so wurde mit einem heißgemachten Stahl, der in der Küche zum Messerschleifen diente, ein Loch eingebrannt. Dieses wiederum mußte mit einem genau passenden, der Länge nach zweigeteilten Plexiglas-Einsatz geschlossen werden. Zwischen die beiden runden Glasscheiben legte man nun das ausgeschnittene Kopfbild seiner Liebsten usw. Mit einer heißen Stopfnadel wurde schließlich noch die Öse für ein Kettchen eingeführt. Den größten Zeitaufwand verursachte das Polieren der Flächen und Kanten. Dies geschah meist abends im Zelt. Während wir uns unterhielten, polierten wir unsere Errungenschaften auf Klopapierrollen. Ich habe ein solches Herz gebastelt und, mit Irmgards Bild versehen, mit nach Hause gebracht, nach Jahren aber, ohne diesen Inhalt, einem lieben, jungen Freund zu dessen Hochzeit als Glücksbringer geschenkt.

Obwohl wir abends vor allem der Ruhe pflegen wollten, gab es doch ein reges Lagerleben. Zur Zerstreuung der Gefangenen diente ein großes Lagerorchester, das fast ausnahmslos Swing und sonstige Tanzmusik spielte. Seine Besetzung war entsprechend. Ferner trat gelegentlich ein Gitarrenund Mandolinen-Orchester, verstärkt durch Zieh- und Mundharmonikas, auf. Unter den letzteren war ich zu finden. Wir boten überwiegend Volksmusik, Wanderlieder usw. Es gab auch einen Boxring, und wir hatten scheinbar gute Gladiatoren unter uns. Ich verstehe davon nichts. Aber die Begeisterung der Menge am Abend bei Scheinwerferlicht war beachtlich. Die gleich danebenstehenden Wachtürme waren an solchen Abenden von farbigen US-Soldaten überbesetzt.

Wir hatten übrigens nur farbige Wachsoldaten. Sie waren unsere Freunde geworden. Irgendwie fühlten sie sich mit uns verbunden. In der ganzen Area erledigten sie die weniger angenehmen oder riskanteren Aufgaben, z. B. als Chauffeure von Tanklastzügen, Munitionstransporten, Feuerwehrwagen usw. Sie hatten auch separate Küchen, und unsere dort 
eingesetzten Mitgefangenen hatten es besonders gut. „,Du weißer Gefangener, ich schwarzer Gefangener" war gelegentlich zu hören.

Bei den sportlichen Aktivitäten fehlte natürlich Fußball nicht. Hier wurden Kompanie-Meisterschaften ausgetragen. Im Kirchenzelt wurde nicht nur das Wort Gottes verbreitet. Es gab auch weltliche Kulturgenüsse zu hören. Zwei Konzertprogramme habe ich gerettet. Ich hörte am 17. Dezember 1945 und 9. Januar 1946 Musik von Bach, Händel, Beethoven, Mozart, Schubert u.a. unter Mitwirkung eines Kirchenchores, eines Kammer-Orchesters sowie mehrerer Solisten (Klavier, Violine, Cello und Bariton). Aber alle Kurzweil im Lager konnte unsere tristen Gefühle nicht aufhellen, Monat um Monat ohne Post von zu Hause zu sein, ja nicht einmal selbst geschrieben haben zu dürfen. So wurde ich am 14. Oktober 1945 ohne heimatliche Geburtstagsgrüße 24 Jahre alt. Um dieses Datum herum hatten wir für ca. drei Wochen in unserem Küchenareal keine US-Truppen stationiert und zu versorgen. Weil die Nachbareinheiten unsere Zelte teilweise beanspruchten, war der verbliebene Rest für die Unterbringung einer normalen US-Einheit zu gering. Das hielt uns aber nicht davon $a b$, Tag für Tag auszurücken. Inzwischen konnten wir dies tun, ohne von einem GI begleitet zu werden. Wir meldeten uns einfach ab und taten den ganzen Tag über nichts. Einerseits hatten wir noch jede Menge Verpflegungsvorräte in der Speisekammer. Zum anderen konnten wir bei unseren mitgefangenen Freunden im Verteiler-Depot fassen, was wir brauchten. Da überraschte uns eines Tages ein rothaariger Leutnant als Küchen-Kontrolleur. Einrichtung und Ausstattung waren bei uns nicht zu beanstanden. Er vermißte aber an unseren grünen Ami-Pullovern, die wir jetzt im Herbst trugen, die aufgemalten PW-Zeichen, die uns als Gefangene auswiesen. Am nächsten Tag wollte er wiederkommen und Vollzug gemeldet haben. Ein allzeit lustiger Vogel unseres Teams, aus Kassel gebürtig, bemalte daraufhin seinen Pullover vorne und hinten sowie an beiden $\ddot{\text { rr- }}$ meln total mit PW-Zeichen. Es ist bezeichnend, daß der US-Leutnant sich nicht auf den Arm genommen fühlte und mit einem ,o.k." fortging. Tage später kam indessen ein Lkw, der den Inhalt unseres ganzen Vorratsmagazins übernehmen sollte. Auf dem Weg dorthin standen unsere sechs leeren Abfalltonnen. Ich hatte sie seit Tagen auf den Kopf gestellt, damit niemand seine Abfälle hineinwarf. Das hätte ja unnütze Arbeit einer sonst nichtstuenden Kochgruppe gegeben. Nun legten wir Vorräte, die wir behalten wollten, blitzartig in die aufgestülpten Tonnen. Was wir ohnedies loswerden wollten, wie Trockenei, Trockenmilch, gedörrte Pflaumen usw., warfen wir auf den unbewachten Lkw. Der Leutnant stand ja im Magazin, und der Lkw-Fahrer war einer von der Gilde der Gefangenen.

Am 14. Oktober nun durchbrachen wir die heilige Essensordnung der US-Army. Es gab Klöße von rohen Kartoffeln und Braten in echt fränkischer Art, wie sich das für einen Nürnberger gehörte. Die Zeltgemeinschaft innerhalb der Kompanie Nachtigall überreichte mir gemeinsame 
briefliche Grüße, ergänzt durch das Foto eines Pin-up-Girls und ein kleines Gedicht:

Wir wünschen all' aus ganzem Herzen

fürs nächste Jahr nur Gutes Dir.

Der Liebe allergrößte Freuden,

Gesundheit und ein Maßel Bier.

Doch feierst Du demnächst zu Hause

Geburtstags-Liebes-Seligkeit;

dann denk ein wenig der Banausen

aus Callas' „Let's go“ - Ewigkeit.

Es folgten neunzehn Unterschriften der Zeltkameraden.

Am 19. Dezember 1945 erhielt ich das erste Lebenszeichen aus der Heimat, eine Suchkarte von Irmgard, die am 2. November aufgegeben war. Ich selbst durfte meine erste Karte am 5. Januar 1946 und den ersten Brief am 13. Januar 1946 auf den Weg bringen. Neun Monate waren wir somit ohne jede Verbindung mit der Heimat. Und wieder stand Weihnachten bevor, ein weiteres Mal in weiter Ferne. Unser Beruf brachte es mit sich, daß wir an Weihnachten Dienst taten wie an anderen Tagen auch. Die Amis hatten auch an diesen hohen Feiertagen Hunger. Mitten im Lager stand ein großer Weihnachtsbaum. Am frühen Morgen spielten Bläser Weihnachtsklänge, die weit über alle Zelte hinweg erklangen.

Die US-Soldaten feierten den Heiligen Abend und den 1. Feiertag. Ihre Christbäume waren kunterbunt geschmückt. Sie waren guter Stimmung. Für sie alle stand ja die unmittelbare Rückkehr in die Heimat bevor. „Als Sieger kehre heim." Zum Mittagessen gab es Truthahn, wie auch an anderen hohen amerikanischen Feiertagen. Wir waren davon nicht begeistert. Dieses Essen war im Rahmen der knapp verfügbaren Kochzeit besonders arbeitsaufwendig. Die Truthähne kamen tiefgefroren. Unsere Köche schwitzten gewaltig, weil sie die großen Vögel alle erst zum Braten vorbereiten mußten. Und das für mehrere hundert Soldaten. Wenn es stimmt, daß der Truthahn siebenerlei Fleisch liefert und das beste davon die Brust ist, dann hat das Kochteam allerdings das Beste vom Besten gegessen. Bei unseren ausgefüllten Arbeitstagen haben wir von Weihnachtsfeiern im eigenen Lager nichts mitbekommen. Ich habe jedenfalls keine Eindrücke behalten. Aber Rückschau hielten wir auf das Jahr 1945, als wir abends vor dem warmen Kanonenofen saßen. Aus allen Zeltspitzen lugten nun Ofenrohre und qualmte der Rauch. Erst vor wenigen Tagen und Wochen, je nach Glück der einzelnen Zeltgemeinschaft, hatten wir nach und nach eiserne Kanonenöfen organisiert. Ein anderer Weg blieb uns nicht. Bei der US-Army gab es keine solchen Öfen. Wir „Köche“ als Frühaufsteher und Spätheimkehrer kamen für die Ofenbesorgung nicht in Frage. Weiß der Kuckuck aber, woher diese Öfen alle kamen! Die geheizten Zelte waren der letzte Schrei an Wohnkomfort in amerikanischer Kriegsgefangenschaft. Voraus ging im Herbst 1945 der Bau von Doppelbetten, eine ent- 
scheidende Kultivierung unseres Gefangenendaseins. Hatten wir doch fast ein halbes Jahr auf dem Boden Frankreichs gelegen, das entsetzliche Lager in Worms nicht vergessend. Nicht, daß unsere Gewahrsamsmacht nun Betten verteilt hätte, o nein. Eines schönen Tages organisierte ein Kommando allerlei Holzvorräte. Bald darauf begann ein lustiges Sägen und Nageln. Als unsere amerikanische Lageraufsicht nichts anderes dazu zu sagen wußte als ,o.k.“, dauerte es nur wenige Tage, und Tausende von Landsern lagen in doppelstöckigen Betten. Unsere inzwischen längst irgendwo ,abgestaubten“ See-Säcke lagen und standen aber immer noch im Dreck. Wie Abhilfe schaffen? Eine lustige Geschichte mit typisch amerikanischem Ausgang steht am Beginn der Holzbodenproduktion. Eine Zeltgemeinschaft machte hierzu den Anfang. Man brachte lange Bohlen mit nach Hause und nagelte darauf ebenfalls organisierte Bretter, deren Länge der vollen Zeltbreite entsprach. Als unsere amerikanische Aufsicht das Werk betrachtete, war man nicht einverstanden. Solches Holz war für uns zu kostbar. Es durften nur Bretter von unter einem Meter Länge, also Abfallholz, verwendet werden. Der Offizier sprach's und ging. Daraufhin rissen die schlauen Zeltler die Bretter wieder heraus, sägten sie auf ca. 90-95 cm ab und bauten sie wieder ein. Der Ami fand's ,o. k. " und grinste sich eins.

Es versteht sich nun fast von selbst, daß plötzlich ungeahnte Mengen von Balken und Brettern ,gefunden" wurden. Es dauerte nur ein bis zwei Wochen und alle Zelte hatten den gleichen neuen Komfort.

Welchen Humor die Amis an den Tag legten, zeigt ein weiteres Beispiel: Ein Wettbewerb wurde ausgerufen. Die schönsten Zeltvorgärten sollten prämiert werden. Es gab vor allem Zigaretten zu gewinnen. Irgendwelche Verzierungen aus Stein, Holz und ähnlichem hatten die Zelte schon vorher aufzuweisen. Diesmal machte sich eine Zeltbelegschaft den Jux, mit kleinen Steinen folgenden Satz in die braune Erde bei Marseille zu setzen: „Wer nicht arbeitet, soll wenigstens gut essen." Der Ami ließ sich das übersetzen, lachte und prämierte auch dieses Zelt. Zu unserer Kultivierung zählte auch der Naßbereich. Wir hatten hier ausreichende Waschgelegenheiten und konnten täglich duschen. Weil Wasser nach wie vor kostbar war, hieß es aber: eine Minute Duschen, eine Minute einseifen, eine Minute Duschen. Kein Zweifel, daß man auch in dieser kurzen Zeit sauber wird. Wir konnten uns kaum mehr vorstellen, wie schrecklich die hygienischen Verhältnisse im Lager 404 waren. Nur alle paar Wochen bekamen wir damals Wasser. Auf halbhohen Holzgestellen waren US-Soldatenhelme umgestülpt in Löcher eingesetzt worden. Das waren die Waschbecken. Pro Mann erhielten wir dann etwa einen Liter Wasser. Das mußte von Kopf bis Fuß reichen. Meinen Spiegel hatte man mir abgenommen. Als Scherben wäre er ja noch eine Waffe gewesen. So polierte ich mir die Deckelseite einer Konservendose und konnte mich einigermaßen darin erkennen. Immerhin wollte ich mich mit dem gleichen Wasser und stets der 
gleichen Rasierklinge ja auch rasieren, wenn's auch weh tat. Wäschewechsel erübrigte sich mangels Masse.

Aber das war jetzt vorbei.

Mit Anbruch des neuen Jahres vermehrten sich die Gerüchte über eine baldige Entlassung. Wir wußten, daß das Lager 404 inzwischen ziemlich leer war. Zigtausende waren in den letzten Monaten in den Arbeitseinsatz gekommen. Die deutschen Lagerführungen in 404 hielten noch ihre Stellungen, so gut sie konnten. Soweit sie in Arbeitskommandos gesteckt wurden, ging es ihnen berechtigterweise sehr schlecht. Hatten sie doch erheblichen Anteil am geschundenen Dasein vieler Gefangener. Sie bereicherten sich, schikanierten, ließen exerzieren, robben und mit der Nase Steine rollen. Sie ernährten sich auf Kosten der Allgemeinheit hervorragend. Einige wurden von aufgebrachten Gefangenen, die nicht vergessen konnten oder besonders gelitten hatten, erschlagen. Für mich bleibt festzuhalten, daß die Gewahrsamsmacht USA im Lager 404 offenen Auges all diese Schikanen geduldet hat und sich dabei auch noch höchst zweifelhafter jugoslawischer Posten bediente, das Käppi mit dem Sowjetstern garniert.

Ende Januar sollte unsere Stunde der Befreiung schlagen. Ganz offiziell wurde uns die bevorstehende Entlassung mitgeteilt. Wir mußten zur Einteilung von Transportzügen noch einmal für einige Tage, höchstens Wochen in das Lager 404. Der Jubel im Lager 416 war unbeschreiblich. Wir konnten unser Glück nicht fassen. Viele weinten vor Freude. Endlich nach Hause in den Schoß der Familie. Andere waren voller Sorge. Es mußte sie bedrücken, nicht zu wissen, wo sie ihre Schritte hinlenken sollten. Sie waren ohne Heimat. Diese war jetzt russisch, polnisch oder tschechisch. Sie hatten nicht die geringste Ahnung, wo ihre Lieben geblieben waren. Gar mancher gab als Heimatort jenen seines besten Kameraden an. Auch mein Herz lief über vor Glück, als wir nach langen Monaten wieder einmal USSattelschlepper bestiegen, um die erste Etappe nach Hause zurückzulegen. Wir trafen in 404 ein. Zur Entlassung mußten wir unsere Kriegsgefangenenkleidung gegen schwarz gefärbte US-Drilliche eintauschen. Transporte wurden zusammengestellt, von jeweils ca. 1500 Mann Stärke. Das Essen war hier inzwischen wesentlich nahrhafter geworden, als noch im Frühsommer 1945. Dies war nicht mehr das berüchtigte Hungerlager, sondern das heißersehnte Entlassungs-Camp. Eines Tages wurde ein Kriegsgefangener mit einem Körpermaß von über $1,80 \mathrm{~m}$ gesucht. $\mathrm{Zu}$ besetzen war der Posten eines „Pfeifen-Mannes", der am Lagertor Signal zu geben hatte, sobald ein Offizier das Lager betrat. Die Kameraden in meiner näheren Umgebung hänselten mich und meinten, ich sollte mich bei 1,85 m Länge doch melden, um hier beim Stamm-Personal eingereiht zu werden. Ich tat dies aber nicht, denn ich wollte so schnell wie möglich nach Hause. Wie grausam sollte ich mich täuschen. 
Februar 1946:

\section{Statt Heimkehr Übergabe an die Franzosen}

Nach meinen Aufzeichnungen, gestützt auf die 1946 geführte Korrespondenz mit Irmgard, war es am 6. Februar 1946, als morgens auf den Wachtürmen nicht mehr farbige Amerikaner standen, sondern noch dunkelhäutigere französische Kolonialsoldaten. Die amerikanische Flagge war durch die französische Trikolore ersetzt worden. Vor den Toren sah man französische Offiziere und andere Dienstgrade. Man hatte uns, Tausende hoffnungsfroher Menschen, in aller Heimlichkeit an die Franzosen übergeben. Wir fühlten uns verraten und verkauft. Unbeschreibliche Szenen sollten sich in den nächsten Tagen abspielen. Selbstmorde und Selbstverstümmelungen häuften sich. Mehrmals wurden wir von den Amerikanern und Franzosen gezählt. Nie stimmte die erwartete Kopfzahl. Fluchtversuche endeten tödlich im Stacheldraht. Die französischen Militärärzte wurden aktiv. Die Untersuchung geschah höchst oberflächlich, d.h. rein äuBerlich. Wir fühlten uns wie am Sklavenmarkt. So ähnlich mußten einst die Negersklaven von kaufwilligen Amerikanern behandelt worden sein. Es gab nur ein ,,arbeits- oder arbeitsunfähig“. Mit den mir noch verbliebenen Französischkenntnissen wollte ich dem untersuchenden Stabsarzt mit dem Satz ,J'ai mal au cœur" ein Herzleiden vortäuschen. Er antwortete aber nur ohne lange Überlegung: „Tu travailleras dans un bureau." Als ob er mein Schicksal geahnt hätte, schon bald hinter einem Schreibtisch zu arbeiten. Wie Schweine und Rinder auf dem Schlachthof wurden wir alle gestempelt. Ich erhielt ein ,A“ (arbeitsfähig) von blauer Farbe auf den Handrücken gedrückt. Der Stempel war gegen Wasser und heißen Kaffee resistent und hielt mehrere Tage. Ich war endgültig in französischer Kriegsgefangenschaft. Und dies nicht im Kriege, auch nicht am 8. Mai 1945 , sondern am 6. Februar 1946.

$\mathrm{Zu}$ unserer damaligen Situation ist zu sagen, daß nach Zitaten aus dem „Bericht der Wissenschaftlichen Kommission der Bundesregierung zur Geschichte der deutschen Kriegsgefangenen des zweiten Weltkrieges“ nach Kriegsende 1065000 deutsche Soldaten in französischem Gewahrsam waren. Nur ein kleiner Teil von ihnen, nämlich 237000 , waren von französischen Streitkräften gefangengenommen worden. Die Masse der Deutschen in französischen Lagern war ursprünglich in amerikanischer Gefangenschaft und anschließend an die Franzosen übergeben worden, die darauf bestanden.

Aus einem Buch, welches sich mit der Auswertung des Berichtes der oben zitierten Kommission befaßt, entnehme ich auszugsweise folgendes: „Im Sommer 1945 reisten Delegierte des Internationalen Roten Kreuzes durch die Lager in Frankreich, in denen deutsche Kriegsgefangene festgehalten wurden. Die Abgesandten der Hilfsorganisation verfaßten in Genf unter dem Datum des 21. August 1945 eine Denkschrift mit be- 
stürzendem Inhalt. Sie stellten fest, da $B$ der Nahrungsmangel das Leben von 200000 deutschen Kriegsgefangenen unmittelbar gefährde. 2000 Gefangene seien so krank, daß kaum Aussicht auf ihre Erholung bestehe. 2000 Gefangene seien so schwach, daß sie keine Nahrung mehr aufnehmen könnten und künstlich ernährt werden müßten. Und: Für 600000 Gefangene in französischen Lagern gebe es nur ungenügende Unterkünfte - ein angesichts des bevorstehenden Winters möglicherweise lebensgefährlicher Zustand.

Die Amerikaner wurden alarmiert. Sie weigerten sich daraufhin strikt, weitere deutsche Kriegsgefangene an die Franzosen auszuliefern. Begründung: „Die Deutschen in französischer Hand sind ungenügend ernährt, untergebracht und bekleidet.“

Mehr noch: Das US-Hauptquartier in Frankfurt am Main forderte von der französischen Regierung, 200000 Gefangene, die wegen ihres Gesundheitszustandes arbeitsunfähig waren, wieder an die Amerikaner zu überstellen. Tatsächlich übergaben die Franzosen im Herbst und Winter des Jahres 1945 an die Amerikaner rund 70000 deutsche Soldaten, allesamt krank und arbeitsunfähig. Sie wurden in die Heimat entlassen."

Es wird hier offensichtlich verschwiegen, daß die Amerikaner trotz ihrer gewonnenen schrecklichen Erkenntnisse erneut nachgiebig wurden, und diesmal wohl wissend, was sie taten. Sie ließen sich mit $70000 \mathrm{Gefan}-$ genen abspeisen und schickten anfangs 1946, ich weiß nicht wie viele, aber mindestens Zehntausende zu den Franzosen. „Verliehene“ Menschen, als ob man schnell mal so ein Fahrrad verleiht. Selbst im Mai 1946 sollte deutsche Soldaten dieses Schicksal noch ereilen. Ich komme darauf noch zurück. Und in den spärlichen deutschen Zeitungen war dann zu lesen: „Die Amerikaner haben keine Gefangenen mehr. Die Letzten verlieBen am 22.7.46 die USA." Unser seelisches Martyrium erreichte seinen absoluten Höhepunkt, als wir wieder in ein anderes Cage eingeschleust wurden und abends in der Dämmerung plötzlich durch den Maschendraht im benachbarten Cage entsetzlich heruntergekommene Gestalten sahen. $\mathrm{Zu}$ Skeletten abgemagerte Kriegsgefangene in alten, zerlumpten und zerrissenen Wehrmachtsuniformen, barfuß in Holzpantinen, und das im Februar. Das waren also jene Kameraden, die von den Amerikanern an die Franzosen ,ausgeliehen“ waren und zurückgeholt wurden, um krank und elend nach Hause zu fahren. Es war schier unerträglich, daran zu denken, daß uns ersatzweise nun das gleiche Schicksal widerfahren konnte.

Noch waren wir von den Franzosen nicht gefilzt. Spontan ergriff einer einen großen Papiersack, in welchem sonst das Weißbrot der Amerikaner transportiert wurde. Wir warfen an Tabak hinein, was wir zu entbehren glaubten. Das war eine ganze Menge, denn wir hatten als ,aktive“ Raucher viel Tabak gespart. Wir schleusten den Sack in das Nachbarcage, und Gott sei Dank ging die Verteilung einigermaßen friedlich vonstatten. Am nächsten Tag nahm man uns wieder alles ab, was französische Soldaten 
brauchen konnten. Selbst eben erst für den „Heimtransport“ gefaßte Tabakrationen wanderten über den Tisch.

Wir blieben nur noch wenige Tage mit kummervollen Mienen in Südfrankreich. Eines Tages hieß es ,Gepäck aufnehmen“ und unter strengster Bewachung verließen wir das Lager 404 bei Séptèmes-les-Vallons in Richtung Bahnhof. Ich bekenne, weich in den Knien geworden zu sein, als ich den Seesack schulterte und zum Bahnhof marschierte. Ich mußte mich zusammennehmen, um nicht zusammenzubrechen. Quo vadis? Niemand konnte unser weiteres Schicksal vorausahnen. Wir fuhren die ganze Nacht in Richtung Norden. Endlich konnte ich im knallvollen Güterwagen einschlafen. Am ,Transport-Komfort“ hatte sich für Kriegsgefangene seit einem Jahr nicht das Geringste geändert. Wir lagen Mann an Mann auf dürftigem Stroh am Boden.

Träumt jeder Mensch in seinem Leben wohl tausend und mehr Träume, so bleiben diese jedoch kaum haften. Ich habe in Erinnerung behalten, daß mir im Traum auf dem Transport von Südfrankreich nach Savoyen ein Güterzug entgegenkam. In einem Waggon sah ich lauter Urnen und darunter eine, welche meinen Namen trug. Es mag Spinnerei sein, sich mit der Auflösung dieses Traumes zu befassen. Ich legte diese Erscheinung so aus, daß ich in ein neues Leben eintrat. Das bisherige war gestorben. Es galt, sich Neuem zuzuwenden und, wie schon seit Jahren, wieder einmal die Ohren steif zu halten.

Wir erreichten unser Ziel, das Dépôt de P.G. 142 in Pont d'Ain. ${ }^{2}$ Es lag in ehemaligen Kasernengebäuden, durchwegs Flachbauten. Was lag näher, als nach unserem Eintreffen gleich wieder gefilzt zu werden. Es gab immer noch etwas abzunehmen. Ich war bei der Mitnahme meines Besitzes in das Lager ungewöhnlich erfolgreich, indem ich dem filzenden adjudant-chef zufällig meine Brieftasche mit sehr vielen Fotos meiner überaus hübschen Irmgard vor die Augen kommen ließ. Er betrachtete diese Bilder eingehend und ließ mich dabei meinen See-Sack aus- und wieder einpacken, ohne sich weiter darum zu kümmern. Die Fotos schienen ihm interessanter. Und es gab ja noch mehr inhaltsreiche Säcke. Im Lager endgültig angekommen, wurden wir von den bereits seit 1944 hier darbenden Gefangenen, die stets nur bei den Franzosen waren, ob unseres guten körperlichen Zustandes bestaunt. Mit ca. 50 Mann belegten wir eine der vielen Baracken, die schmucklos, eine neben der anderen, da standen.

Als wir in den ersten Tagen bemerkten, wie eifersüchtig die alten Insassen des Lagers auf die richtige Menge ihrer Zuteilung achteten, lachten wir noch. Drei Wochen später hatten wir uns angepaßt. Wir waren längst wieder hungrig geworden, und der Hunger war das fast einzige Gesprächsthema. Gab es im Lager 404 von amerikanischen Lebensmitteln eben viel zu wenig, so bestand unsere Ernährung hier hauptsächlich aus Wicken und Sojamehl bzw. Lauchgemüse. Wir hatten, mehr als uns lieb war, zu den typisch französischen Toiletten zu rennen; denn Durchfall 
war an der Tagesordnung. Morgens gab es Kaffee primitivster Art. Mittags eben Wicken, Lauchgemüse mit Sojamehl, selten etwas anderes. Abends erhielt jeder $300 \mathrm{~g}$ Brot sowie einen gestrichenen Eßlöffel voll Zucker. Einmal in der Woche faßten wir ein Stückchen Käse von Daumennagelgröße, ein anderes Mal eine Scheibe Blutwurst ohne jeden weiteren Inhalt. Nach drei Wochen hatten auch wir in der Baracke der Neuankömmlinge eine „Brotwaage“. Sie bestand aus einem „Waagbalken“, in Form einer einfachen Holzleiste, der an einer Schnur hing. Links war eine Schale an Bindfäden aufgehängt, die „Gewichte“ aufnehmen konnte. Als solche dienten Kieselsteine, die in der Küche abgewogen und mit Tintenblei markiert waren. Sie entsprachen einem Gewicht von $300 \mathrm{~g}$. Auf der anderen Seite der Waage hing ein mehrere Zentimeter langer Holzdorn, dessen Eigengewicht mit der Schale identisch war. Dieser Holzdorn wurde in ein Brotviertel gespießt. Das Viertel eines Brotlaibes entsprach aber nur grob $300 \mathrm{~g}$. Ergab sich ein Ungleichgewicht, so wurde entsprechend mit Brotscheiben aufgewogen. Blieb am Ende eine Scheibe übrig, so wurde diese auf sämtliche Barackeninsassen aufgeteilt(!). Jeder bekam einen Brotwürfel. Ich habe noch jenen älteren Mitgefangenen vor Augen, der im Doppelstockbett mein Untermann war. Abend für Abend sammelte er mit seinem Löffel auch noch die letzten Brosamen ein, damit von seinem Tellerinhalt wirklich nichts verlorenging.

Für uns alle war dieser Rückfall in primitivste Zustände außerordentlich deprimierend. Dazu war es im Februar noch sehr kalt, und die Barakken waren nicht geheizt. Jedermann strebte danach, so bald wie möglich für ein Arbeitskommando eingeteilt zu werden, wenngleich keiner wußte, ob er damit vom Regen in die Traufe kommen würde oder nicht.

Zur kulturellen Betreuung hatten wir ein Lagerorchester, das, wie üblich, Tanzmusik von sich gab, gelegentlich auch Operettenmelodien. Ferner existierte ein Lagerchor. Eines Abends sah ich diesen Chor durch das Fenster eines „Kultur-Saales“ proben. Die Sänger hatten den Vorzug, daß während ihrer Übungen in einem Kanonenofen ein bescheidenes Reisigfeuer brannte. Die Gruppe stand im Halbkreis, der zweite Baß dem Ofen am nächsten. Anderntags meldete ich mich als Chormitglied zum zweiten $\mathrm{Baß}$. Zu meiner Entschuldigung muß ich sagen, daß ich zeit meines Lebens ein sangesfroher Mensch bin, ein Erbe von Vater und Mutter. Aber der erste $\mathrm{Baß}$ wäre für meine Stimme vielleicht weniger anstrengend gewesen. Wesentlich war indessen damals, ein bis zwei Stunden lang so nah wie möglich am Ofen zu verbringen.

Täglich wurde zu irgendwelchen Einsätzen aufgerufen. Wichtig waren für die Auswahl die erlernten Berufe. Dank meiner in der Schule und 1943/44 in Nordfrankreich erworbenen französischen Sprachkenntnisse landete ich nach einigen Wochen in der Schreibstube der Lagerverwaltung als Schreiber und Dolmetscher. Letzteres war nötig, wenn mit Franzosen zu sprechen war, die Gefangene abholten oder zurückbrachten. 
Das Frühjahr 1946 verstrich, ohne daß wir auch nur das Geringste davon mitbekommen hätten. Das Lager war trostlos öde. Das einzig Bemerkenswerte war im Mai ein Neuzugang an Kriegsgefangenen. Sie kamen aus den USA via Le Havre. In den Staaten wurden sie zur „Entlassung“ eingeschifft und in Le Havre den Franzosen übergeben (,geliehen“). Welch ein Betrug, noch ein Jahr nach Kriegsende. Und jetzt hatten die Amerikaner keine Gefangenen mehr. Also hatten sie ihre doch ,verschenkt"? Die Postverbindung war seit Januar unterbrochen. Endlich, im April, konnte ich per Gefangenenpost-Formular erste Nachricht nach Nürnberg geben. Und diese konnte nicht den Eindruck vermitteln, daß ich bald nach Hause käme. Auch eine Blinddarm-Entzündung Mitte Mai war für eine Entlassung nicht ausreichend. Das Erinnerungsträchtigste an dieser Erkrankung war die im Krankenrevier verabreichte Milchsuppe mit Zwieback. Erst am 2. Juni 1946 erhielt ich, nach dem 19. Dezember 1945, zum zweiten Male Post aus der Heimat.

\section{Juni 1946: Haupt-Vertrauensmann für 5000 Gefangene}

Ende Juni wurde anläßlich eines Appells nach Gefangenen gefragt, die französisch sprachen. Außer mir meldeten sich nur noch drei Kameraden. Wir hofften auf ein Kommando, wo uns das Wissen um die französische Sprache zum Vorteil gereichen könnte. Darum ging es aber nicht. Vielmehr wurden Kandidaten gesucht, die als Nachfolger für den scheidenden Hauptvertrauensmann des Dépôts in Frage kamen, der nach Hause durfte. Zu meiner nicht geringen Überraschung wurde ich zum Nachfolger ausgewählt. Vielleicht haben mein Berufsbild und meine Kenntnisse um den Papierkram beim Militär den Ausschlag gegeben. Nach der Genfer Konvention ${ }^{3}$ war es Sache der Gefangenen, ihren Hauptvertrauensmann selbst zu bestimmen. Die Forderung der Gewahrsamsmacht war indessen, daß dieser ihre Sprache sprechen müsse.

Am 25. Juni 1946 übernahm ich mein neues Amt. Noch nicht 25 Jahre alt, war ich damit zum Verantwortlichen für über 5000 Gefangene gegenüber der französischen Lager-Kommandantur geworden. „Welch eine Wandlung durch Gottes Fügung." Diesen Satz sagte schon einmal jemand. Aber hier war keine Schlacht geschlagen worden. Es ging darum, von einem Tag auf den anderen auf das Schicksal tausender mitgefangener Kameraden Einfluß zu nehmen, und zwar so positiv wie möglich. Eine Verlegung der Dépôts nur wenige Tage später, im Juli, nach Bourg en Bresse, kam mir glücklicherweise zu Hilfe. Nun waren wir nicht mehr auf dem flachen Lande in dörflicher Umgebung, sondern in einer großen Stadt mit entsprechendem wirtschaftlichem Hintergrund. Das sollte für uns nicht unwichtig werden. Nach wie vor waren wir Gefangenen im Dé- 
partement de l'Ain eingesetzt, was vielleicht einem deutschen Regierungsbezirk entspricht. Untergebracht waren wir in der Caserne Brouet, in erdgeschößigen Ziegelbauten.

An unserer sozialen Struktur hatte sich zunächst nichts geändert. Ein Saal unseres Hauptgebäudes wurde für die Kirche reserviert. Sie diente beiden Konfessionen, und wir hatten einen evangelischen und einen katholischen Pfarrer unter uns. Das waren nach der Genfer Konvention sogenannte „geschützte Personen“, die sich außerhalb des Lagers frei bewegen konnten. Sie taten dies auch reichlich per Fahrrad und besuchten unentwegt die verschiedenen Kommandos. Die Fensterscheiben des Kirchensaales wurden mit sehr viel Liebe und außergewöhnlichem Geschick bunt bemalt. Gleich einer Kathedrale konnten wir so das Sonnenlicht verzaubern.

Ein weiterer Saal stand für Tischtennis zur Verfügung und wurde täglich rege benützt. Selbst Meisterschaften wurden ausgetragen. Aber in der Caserne hielten sich außer dem Stammpersonal von ca. 150 Mann in aller Regel nur etwa 150-250 weitere Gefangene auf, die entweder krank waren und in dem dazugehörenden Dépôt-Lazarett lagen oder von ihrem Kommando zurückkamen, also auf neue Einsätze warteten.

$\mathrm{Zu}$ dem im Dépôt-Bereich liegenden Lazarettbau zählte auch eine Zahnstation, die, gemessen am heutigen Standard, unter abenteuerlichen Bedingungen arbeitete. Vorweg muß ich aber sagen, daß dort zwei Nürnberger Landsleute tätig waren. Chef der Station war Dr. Ponater, ein Unterarzt von militärischem Rang, dem der ebenfalls aus der Noris stammende Gefr. Theo Scharold assistierte. Letzterer kam als ,évadé“, ein erfolglos geflohener Kriegsgefangener also, zu uns, nachdem man ihn in unserem Dépôt-Bereich geschnappt hatte. Nach vier Wochen Arrest und dem üblichen Glatzenschnitt landete er recht bald in der Zahnstation, wo er sich erfolgreich bemühte, den armen Zahnkranken die Angst vor dem reichlich derben Unterarzt bzw. dessen karger technischer Ausstattung zu nehmen. Der Doktor betrieb seine uralte Bohrmaschine höchstpersönlich per Fußpedal, um die Umdrehungsgeschwindigkeit des Bohrers den Erfordernissen entsprechend selbst regulieren zu können.

Bei den nötigen Impfprozessen im Dépôt-Lazarett mußte übrigens eine Injektionsnadel, jeweils nur in Alkohol getaucht, für mindestens fünf Gefangene reichen, ehe sie ausgekocht und weiterverwendet wurde.

Die Masse der 5000 Kameraden war auf rund 400 Kommandos aufgeteilt. In einer späteren Lagerzeitung habe ich allen Dépôt-Angehörigen die Kommandogliederung mitgeteilt, und zwar:

Kommando Nr: 1-243 Landwirtschaftlicher Einsatz

250-279 Holzkommandos

300-332 Einsatz zur Rekonstruktion

350-356 Einsatz im Steinbruch

370-375 Industrie Oyonnax 


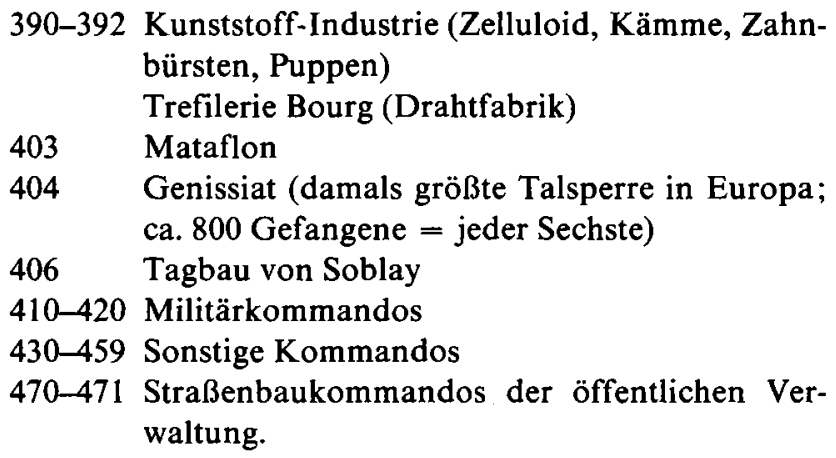

Es galt, die Verbindung zu diesen großen und kleinen Kommandos bis hin zum Ein-Mann-Einsatz zu vertiefen und, wo nötig, die Verhältnisse am Ort zu verbessern. Durch gelegentliche Besuche von seiten der Kommando-Vertrauensleute im Dépôt gewann ich den Eindruck, daß dort vieles im argen lag, geschlagen wurde, Hunger herrschte usw. Andererseits kannten die Gefangenen selbst weder ihre Rechte noch Pflichten, die in der Genfer Konvention niedergelegt sind.

Im Dépôt existierte seit Herbst 1945 eine Lagerzeitung, die von fünf „Redakteuren" verfaßt und mit Tinte von Hand in Blockschrift geschrieben wurde. Mehr als ca. 100-150 Exemplare à vier Seiten kamen dabei nicht zustande. Sie reichten aus, um allenfalls Großkommandos zu versorgen.

Am alten Sitz des Dépôts in Thôl fand ich bereits eine Lagerkantine vor, in der es außer Zigarettenpapier, Mehl, Schuhcreme und ein paar anderen Utensilien wie Knöpfe, Nähgarn usw. nichts zu kaufen gab. Nur die jeweils im Dépôt Anwesenden konnten dort mittels Lagergeld versuchen, ihren Bedarf zu decken. Jeder im Arbeitseinsatz stehende Gefangene erhielt indessen pro Tag einen Lohn von zehn (alten) Franc. Davon wurden fünf auf dem Kommando ausbezahlt. Die restlichen fünf sammelten sich auf dem Konto der Gefangenen unter seiner Nummer im Dépôt. Kam der Betreffende in das Lager zurück, so konnte er den aufgelaufenen Betrag in Lagergeld abheben, aber reichlich wenig damit anfangen. In dem Bestreben, hier Entscheidendes zu verbessern, habe ich folgendes unternommen:

1. Ich habe den Lagerkommandanten gebeten, einverstanden zu sein, da $B$ jeder Gefangene die zweiten 5 Franc/Tag dazu verwenden konnte, bargeldlos, also zu Lasten seines im Lager geführten Kontos, in der Kantine einzukaufen, auch wenn er auf Kommando war.

2. Ich habe den Lagerkommandanten gebeten, mir dabei behilflich $\mathrm{zu}$ sein, daß eine in Bourg ansässige Druckerei unsere bisher von Hand geschriebene Lagerzeitung gegen Entgelt druckte, und zwar in jeweils 1000 Exemplaren à acht Seiten. Das war insofern nicht leicht, als Papier auch in Frankreich ausgesprochene Mangelware war. Es kam 
hinzu, daß die Zeitung ohne jede Werbung und Inserate für jede Drukkerei eigentlich ohne Interesse war.

Der Kommandant hat meine Vorschläge angenommen. Das hieß nun nicht mehr „o.k.“, sondern ,d'accord“. Was nun immer in den nächsten Monaten an bescheidenem Wohlstand ausbrach, war diesen beiden Entschlüssen zu verdanken. Denn: mit der neuen Lagerzeitung erreichte ich alle Kommandos. Ich konnte allen Gefangenen mitteilen, daß sie in der Kantine zu Lasten ihres Kontos einkaufen konnten. Ich informierte per Lagerzeitung über unser Kantinenangebot. Das Kommando bestellte schriftlich per Sammelauftrag unter Angabe von Namen, Gefangenen-Nr. und gewünschtem Gegenstand. Die Preise waren bekannt. Die Kantine packte jede Bestellung sackweise zusammen, und was nicht selbst abgeholt wurde, spedierte man auf dem üblichen Postwege an den Bestimmungsort. Das Rechnungsbüro belastete die Konten der Gefangenen im einzelnen.

Ich habe damit das ausgelöst, was man in der freien Wirtschaft „Versandhandel" nennt. Eine Zeitung gegen Entgelt drucken zu lassen hieß aber, das entsprechende Kapital verfügbar zu haben. Zu diesem Zweck erhob ich auf die Einkaufspreise der Kantine einen Zuschlag von 10\%. Weil unser Kantinenumsatz von bisher ca. 100000 (alten) Franc/Monat, der größeren Nachfrage wegen, sehr rasch auf eine Million stieg und dies auf Dauer, hatte ich genügend Geld verfügbar, um nicht nur die Zeitungskosten zu decken. Für manche Lebensmittelhändler und andere Lieferanten von Gebrauchsgütern waren wir durch diese Umsatzsteigerung ein interessanter Wirtschaftsfaktor geworden. Zwangsläufig vervielfältigte sich unser Angebot. Schließlich gab es Schokolade, Datteln, Weintrauben und andere bisher unerschwingliche Dinge in der Kantine zu kaufen. Der Gewinn aus dem Kantinengeschäft diente schließlich auch dazu, die Verpflegung zu verbessern. Von jetzt an gab es auch abends warme Küche. Der Eintopf wurde kräftiger und bestand längst nicht mehr aus Wicken und Sojamehl. Unseren mitgefangenen ehemaligen SS-Soldaten, überwiegend blutjunge Kerle, die erst gegen Ende des Krieges eingezogen worden waren, ging es speziell auf Straßenbau- und Steinbruchkommandos besonders schlecht. Wie in 404 bei den Amerikanern, bekamen sie auch hier eine Sonderbehandlung. Wir Infanteristen haben im Kriege die Waffen-SS zwar stets beneidet, weil sie besser ausgerüstet, durchwegs motorisiert und besser verpflegt war. Aber schließlich waren das Frontsoldaten wie wir vom Heer. Ich habe sie in Rußland persönlich erlebt. Es gibt keinen Grund, diese Soldaten zu hassen. Vielleicht hat die völlig überflüssige Mißhandlung der Angehörigen dieser Waffengattung schließlich erst dazu geführt, daß hier eine eigene Hilfseinrichtung auf Gegenseitigkeit (HIAG) ${ }^{4}$ ins Leben gerufen wurde. Ob man hier nicht Ursache und Wirkung verwechselt? Ich ließ jedenfalls aus humanitären Gründen fallweise die Verpflegung dieser besonders schweren Kommandos verbessern. 
Wenn wir die kulturelle Betreuung aller Kameraden vertiefen wollten, so bedurfte es hierzu in größerem Umfang als bisher freiwilliger Kräfte, die bereit und in der Lage waren, nach Feierabend für ihre Mitgefangenen zu wirken. Zum Stammpersonal zählten etwa 150 Mann. Nur aus diesem Bereich konnten unsere Künstler und Vortragenden rekrutiert werden. Etwaige Lücken habe ich versucht, über die Lagerzeitung zu stopfen, indem ich auf der letzten Seite, die dem Hauptvertrauensmann vorbehalten war (,Was der PG wissen muß“), nach Musikern und Professoren, Lehrern oder Studenten in höheren Semestern suchte. Diese Leute mußten dann aber tagsüber in irgendeiner Funktion voll einsatzfähig sein. Das Lagerorchester stand. Es ging mir aber darum, den Kammermusikbereich auszubauen. Cello und Bratsche hatte ich bei der YMCA ${ }^{5}$ angefordert, die Spieler waren zu suchen.

Unsere Unterrichtskurse befaßten sich mit Themen wie: Mechanik, Mathematik, Französisch und Englisch. Vortragsreihen galten der Erdkunde, der Kulturgeschichte. Darüber hinaus gab es Einzelvorträge über spezielle, interessante Themen.

Die räumlichen Verhältnisse erlaubten es nicht, Sport im großen Stil zu betreiben. Außer Tischtennis waren Schach- und Skat-Turniere am beliebtesten. Das Lagerorchester fand bei der Masse großen Zuspruch. Kammermusikalische Veranstaltungen wurden von einem kleineren Zirkel Interessierter frequentiert. Aus meiner Programmsammlung entnehme ich: 20. 7.46 Musik von Telemann, Beethoven und Händel, ergänzt durch eine Dichterlesung R. M. Rilke „Die Weise von Liebe und Tod des Cornets Christoph Rilke“".

28. 8.46 Abendliche Feierstunde zur 197. Wiederkehr des Geburtstags von Johann Wolfgang von Goethe. Die ,Schülerszenen aus Faust I und II" wurden umrahmt mit Musik von Telemann. „,Greift nur hinein, ins volle Menschenleben.

Ein jeder lebt's, nicht vielen ist's bekannt Und wo Ihr's packt, da ist es interessant.“

(Faust, Vorspiel auf dem Theater)

28.10.46 Musik- und Leseabend „Aus der Deutschen Romantik“.

Musik von Felix Mendelssohn-Bartholdy.

Gedichte von Joseph Freiherr von Eichendorff. ,,Und Du willst, Menschenkind, der Zeit verzagend unterliegen?

Was ist Dein kleines Erdenleid?

Du mußt es überfliegen."

Klavierstücke aus „Lieder ohne Worte“ umrahmten folgende Eichendorff-Gedichte:

Wanderspruch

Treue

Letzte Heimkehr 


\section{Das zerbrochene Ringlein \\ Mahnung \\ Der Unbekannte \\ Heimweh.}

18. 3.47 Ein Abend mit Wolfgang Amadeus Mozart

unter Mitwirkung von Flöte und Klavier

sowie dem Lagerchor (,Abendruhe, Schutzgeist“).

Wie in langen Kriegsjahren war auch in der Gefangenschaft die große, klassische Musik mein echter Halt. Sie erfüllte mich total, und ich konnte immer wieder von ihr zehren. Sie bleibt ein Leben lang meine große Liebe. Meine erhalten gebliebene, umfangreiche Korrespondenz mit Irmgard weist über Jahre fast in jedem Brief auf musikalische Erlebnisse hin, die ich jedesmal zu schildern versuchte. Ich hatte mit Irmgard vereinbart, eine im Kriege allwöchentliche Sendung, wenn immer möglich, zu hören. In diesen Stunden wollten wir uns gedanklich besonders nahe sein.

Nach unserer Ankunft in Bourg en Bresse bauten wir uns in einem Saal, der allgemeinen Veranstaltungen dienen sollte, einen Boxring, umgeben von vier Pfosten und den Seilen. Auf diesem Podest konnte man boxen oder auch Musik machen oder Vorträge halten. Für ein Theater, an das wir nun dachten, war der Aufbau indessen reichlich unbefriedigend. Wir begannen deshalb, mit Zustimmung des Kommandanten auf diesem Fundament eine richtige Theaterbühne aufzubauen, mit Souffleurkasten und Kulissen mit rückwärtigen, wenn auch sehr knappen Gängen. Es wurde eine vorbildliche Bühne. Wesentlichen Verdienst hatten einige Kameraden, die sich als Bühnengestalter und Kulissenmaler exzellent hervortaten. Nach meiner Erinnerung war einer von ihnen in diesem Beruf bei der Dresdner Staatsoper tätig. Quer von einer Wand zur anderen wurde über die Bühne noch das Motiv eines Nürnberger Kaufmannszuges gemalt. Weil wir aber weder Waffen besitzen noch im Zuge der ,Umerziehung“6 solche malen und damit „verherrlichen“ durften, ließen wir die Spieße und Hellebarden weg. Es war also ein friedlicher Zug. Vom Herbst 1946 bis zum Frühjahr 1947 brachten wir vier Theaterstücke auf die Bretter. Das war mit sehr viel Fleiß aller Beteiligten verbunden, denn für die Vorbereitungen blieben nur die Abendstunden nach getaner Arbeit oder die Wochenenden übrig. Unsere Theatergruppe war so erfolgreich, daß selbst die französischen Soldaten der Verwaltung, häufig elsässischer Abstammung und daher deutsch verstehend, mehr und mehr die Plätze einnahmen. Bis zu vier unserer Kameraden mußten, je nach Programm, in Frauenkleider schlüpfen. Diese fertigten wir in unserer Schneiderei, ebenso wie unser Schuster Damenschuhe produzierte. Was eine Frau auch immer benötigt, schöne Haare in Form einer Perücke, Augenbrauen- und Lippenstift, Büstenhalter (mit Füllung), Damenstrümpfe: alles wurde organisiert. Finanzieller Rückhalt war auch hier der Nutzen aus unserer Kantine. Die Begeisterung der Lagerinsassen über das Gebotene war enorm. 
Mit kleineren Theateraufführungen, Sketchen, Musik und Vortragenden fuhr auch Sonntag für Sonntag ein Lastkraftwagen auf den Straßen des Départements, um unsere großen Kommandos aufzusuchen, die wir vorher an bestimmten Orten zusammentrommelten. Mit diesem Einsatz begannen wir im Spätherbst 1946, und dazu gibt es eine Vorgeschichte. In jenen Wochen ordnete die französische Verwaltung, wohl auf nationaler Ebene, an, daß besonders geeignete und zuverlässige ,Propagandaredner“ durch entsprechende Vorträge auf Kommandos zur „Umerziehung“ beitragen sollten. Ich nahm die Gelegenheit beim Schopf und schlug vor, wenn hierfür schon ein Fahrzeug unterwegs sein dürfe, dann sollte eine darüber hinausreichende kulturelle Betreuung auf den Kommandos stattfinden. Statt eines Pkws fuhr nach dem ,,d'accord“ des Kommandanten unser alter Panhard-Lkw durch die Lande. Über die Betreuung der Kommandos im Département Ain berichtete die Lagerzeitung z. B. für den Zeitraum Februar/März 1947: ,In den Monaten Februar und März war die kulturelle und politische Betreuung wieder recht rege. Jeden Sonntag war der Vortragsredner zusammen mit der Künstlerschar unterwegs, um den Kameraden draußen auf den Kommandos Anregung und Abwechslung zu bieten. An den Wochentagen erstreckte sich die Betreuung auf die Lager Bourg und Vennes (ein Nebenlager von Bourg; d. V.). Von den Kommandos wurden in erster Linie die größeren berücksichtigt und darunter vor allem die Rekonstruktionskommandos. Die dem jeweiligen Betreuungsort nahe liegenden kleineren Kommandos wurden ebenfalls eingeladen und, soweit die Kameraden abkömmlich waren, haben sie gern der Einladung Folge geleistet. Insgesamt fanden in den beiden Monaten fünfzehn Veranstaltungen statt, an denen über 1800 Kameraden teilgenommen haben.

Den Vorträgen lagen folgende Themen zugrunde:

1. Diktatur und Demokratie

2. Deutsches Sozialproblem auf demokratischer Basis

3. Amerikanische Verfassung

4. Östliche und westliche Demokratie

5. Gedanken über die Erziehung der deutschen Jugend.

Nachstehend geben wir eine Übersicht über die verschiedenen Veranstaltungen der beiden vergangenen Monate:
2. Februar Sathonay
9. Februar Nantua
57 Teilnehmer
23. Februar Thoissey
50 Teilnehmer
23. Februar Leyment
80 Teilnehmer
20. Februar Caserne Brouet
99 Teilnehmer
27. Februar Camp des Vennes
80 Teilnehmer
2. März
Châtilly s. Chalons
250 Teilnehmer
6. März
Caserne Brouet
9. März
Artemare
117 Teilnehmer
100 Teilnehmer
300 Teilnehmer 
16. März

Oyonnax

20. März

Camp des Vennes

23. März

27. März

30. März
102 Teilnehmer

80 Teilnehmer

60 Teilnehmer

200 Teilnehmer

200 Teilnehmer".

Was es für die Gefangenen bedeutete, Besuch aus dem Dépôt zu erhalten, der für Zerstreuung und Information sorgte, ist dem Bericht aus einer anderen Nummer der Lagerzeitung auszugsweise zu entnehmen: „Unser Berichter war dabei“. „Am 16. März, $10 \mathrm{Uhr}$ früh starteten wir 17 Mann hoch in Bourg, und nach zwei Stunden war über gewundenen Serpentinenstraßen das $600 \mathrm{~m}$ hoch gelegene Oyonnax erreicht. Freudig wurden wir begrüßt, brachte doch der mitfahrende Hauptvertrauensmann gleichzeitig Brief- und Paketpost, Zeitungen und Zigaretten für alle dortigen Kommandos mit. Bald waren in einem für diesen $Z$ weck vorübergehend hergerichteten großen Fabrikraum über 100 PGs versammelt, die gespannt und freudig bewegt auf den Beginn der Veranstaltung warteten, auf die sie sich schon lange gefreut hatten. Alle Altersklassen waren unter ihnen vertreten, und alle folgten mit Aufmerksamkeit nach den einleitenden Worten des Hauptvertrauensmannes und einem ernsten Musikstück dem Vortrag unseres Kameraden Lothar. In einfachen, schlichten Worten zeichnete er den Kameraden, von denen mancher nun doch vielleicht bald seiner Entlassung entgegensieht, die Verhältnisse und Lebensbedingungen in der Heimat, wie sie jeder von uns sehen muß, wenn er mit ernsthaftem Willen zur Mitarbeit an den Nachkriegsproblemen zurückkommt. Zwischenrufe und Beifall am Schluß zeigten Mitgehen und Aufgeschlossenheit der Hörer für das Thema und gaben dem Vortragenden die Gewißheit, daß seine Worte nicht umsonst gesprochen waren.

Nach diesem ernsten und gewichtigen Auftakt kam Edgar Gerlatzek mit seiner Lagerkapelle an die Reihe. Ouverturen, Märsche und Tänze in bunter Folge, angesagt und durch humorvolle Einlagen abgelöst von unserem heiteren Stacheldraht-Philosophen Friedrich Schrewe. Starker Beifall, mitgesummte und gesungene Schlagertexte, nicht endenwollende Lachstürme dankten den Meistern des Tones und Wortes. Glänzende Augen und lachende Mienen zeigten uns, wie groß die Freude und Entspannung war, die hier geschenkt wurde.

Nach gastfreundlich dargebotener Erfrischung war die reisende PGKünstlergesellschaft bald wieder mit Instrumenten und Requisiten im Lkw verfrachtet und nach schneller Rückfahrt (für unseren ängstlichen Edgar in den Kurven meist zu schnell) um 20.30 Uhr endlich im Dépôt. Rund elf Stunden sind alle unterwegs gewesen, sicher eine Anstrengung für unsere „Wanderbühne“, denn alle ihre Mitglieder sind ja nur ,,nebenberuflich" Musiker oder Schauspieler und geben Woche für Woche ihren freien Tag, den Sonntag hin, um die Kameraden auf Kommando zu erfreuen. Dankt es Ihnen durch Euren Beifall.“ 
Noch ehe sich aber Wanderbühne und Vortragsredner im Spätherbst auf den Weg machten, fand ich eine Gelegenheit, an Sonntagen Kommandofahrten zu unternehmen. Ein Abbé Pièrre von der Kirche in Bourg bot sich eines Tages bei der französischen Verwaltung an, bei deutschen Gefangenen im Département de l'Ain Gottesdienst zu halten, sofern man ihm für die Reise Wagen und Fahrer zur Verfügung stellte. Abbé Pièrre hatte einmal in Heidelberg studiert und sprach recht gut deutsch. Obwohl wir selbst zwei radfahrende Lagerpfarrer hatten, waren wir von dem Angebot begeistert. Dies um so mehr, als ich auf diese Weise Gelegenheit hatte, im Pkw mitzufahren. Am Lenkrad saß ein PG, an dessen Seite ein bewaffneter Marokkaner, der über Gefährt und Inhalt wachte. Den Fond teilte ich mit dem Abbé. Unsere Unterhaltung hielt ich in französisch, mein Sitznachbar in deutsch. Bliebe noch zu sagen, daß unser hilfreicher Geistlicher einen vorzüglichen Tabak rauchte, der auch in meinem Pfeiflein Platz fand.

Mit den Fahrten durch das herrliche Savoyen zu deutschen Kriegsgefangenen verband Abbé Pièrre - und das war wohl vorausbedacht - Besuche bei seinem jeweils örtlichen Amtsbruder. Dort gab es immer wenigstens ein Huhn im Topf und eine gute Flasche Wein für den Kirchenmann. Ich nützte die Gelegenheit, Sonntag für Sonntag Briefpost und Päckchen auszuhändigen. Außerdem hatte ich zur Aufklärung der Gefangenen über Rechte und Pflichten eine größere Anzahl Hefte beim Internationalen Roten Kreuz beschafft, die ich mit entsprechenden Empfehlungen verteilte.

Der Dezember 1946 war überschattet von zwei bedrückenden Ereignissen. In der Nacht zum 9. Dezember wurde auf die Unterkunft des Kriegsgefangenen-Kommandos in der Trefilerie (Drahtfabrik) von Bourg ein Attentat verübt. Zwei Angehörige der Belegschaft des Werkes hatten in blinder Verhetzung Handgranaten in die Gefangenen-Unterkunft geworfen. Über den Hergang der Tat wurde seinerzeit berichtet, daß zwei maskierte Franzosen, in deutscher Uniform verkleidet, gegen Mitternacht in die Unterkunft eindrangen, die beiden zivilen Wachposten überwältigten und fesselten. Anschließend drangen sie in den Schlafraum und warfen vier Handgranaten. Es gab zwei Tote und mehrere Verletzte. Die Attentäter wurden später dingfest gemacht und unter Anklage gestellt. Nach Wochen mußte ich die Nachricht entgegennehmen, daß die beiden Franzosen freigesprochen wurden. Angeblich haben sie sich zu dieser Tat hinreißen lassen, nachdem sie aus den Zeitungen wiederholt über deutsche KZ-Greuel gelesen hatten. War das also kein Mord? War dieser Freispruch der Weg, um deutsche Kriegsgefangene, die ja in weit überwiegender Zahl keine Nazis waren, sondern arme Schweine, die immer noch die Rechnung anderer mit dem Verlust ihrer Freiheit bezahlen mußten, zu überzeugten Demokraten zu erziehen??

Im Weihnachtsmonat verdichteten sich auch besorgniserregende Mel- 
dungen von unserem größten Außenkommando, der Barrage de Genissiat. Dort wurde die damals größte Talsperre Europas gebaut, unweit der schweizerischen Grenze. Etwa 800 deutsche Gefangene arbeiteten zusammen mit Polen, Tschechen, Afrikanern, Jugoslawen in drei Schichten rund um die Uhr. Die Behandlung des deutschen Kontingents war miserabel. Das galt nicht nur für die französische Leitung an der Baustelle, sondern dieser Zustand war auch hervorgerufen durch ständige Schikanen seitens der anderen internationalen Arbeiter, unter welchen höchst abenteuerliche Gestalten steckten. Es gab Prügel, wenig zu Essen, dünne Suppen und häufig Ausfälle durch Krankheit. Solche kranken Rückkehrer vom Kommando gaben mir ihre Erkenntnisse und Beobachtungen weiter. Ich berichtete hierüber zusammenfassend sowohl der französischen Kommandantur als auch dem Comité International de la Croix Rouge; dessen Vertreter, Monsieur Filliettaz, hatte seinen Sitz in Lyon. Er war Schweizer Staatsbürger und zuständig für ganz Süd- und Ostfrankreich. In diesem Zusammenhang sei gesagt, daß die monatliche Berichterstattung im Umfang von ca. 6-8 Seiten an das Rote Kreuz in Lyon zu meinen regelmäßigen Aufgaben gehörte. Die Berichte durchliefen die Zensur, wurden aber anstandslos akzeptiert.

Meine Demarche hatte Erfolg. Der Kommandant ließ mich nach Genissiat reisen, wo ich für drei Tage und zwei Nächte blieb. Während dieser Zeit ließ ich mir rund um die Uhr, nur von kurzen Schlafpausen unterbrochen, aus den Reihen der einzelnen Arbeitsgruppen Mitteilung über die Zustände machen. Nach drei Tagen war der Kern aller Klagen für mich offengelegt. Nicht nur die Franzosen verschoben die Gefangenenverpflegung kisten- und körbeweise, sondern der deutsche Kommando-Vertrauensmann steckte mit unter der Decke. Das war ihm auch anzusehen. Wohlbeleibt und mit feistem Nacken stand er vor mir. Der Inbegriff des fiesen Charakters.

Bei der abschließenden Sitzung, zu der auch der französische Lagerkommandant mit seinem Sicherheitsoffizier sowie Monsieur Filliettaz geeilt waren, wurde offen über alle Erkenntnisse diskutiert. Ich konnte mich in dieser Runde als „Geschützte Person“, die ich war, gleichberechtigt fühlen. Meine aus taktischen Gründen wichtigste Aussage war, daß der Kommando-Vertrauensmann nicht gewählt, sondern von den Franzosen eingesetzt war. Das sollte sich sofort ändern. Es wurde gewählt. Der neue Mann tat, worauf es ankam, und fernerhin wurden die Nachrichten aus Genissiat immer erfreulicher. Das Essen wurde besser, Zerstreuung wurde geboten in Form von Musik, Fußball- und Pingpongspielen. Zwar waren die räumlichen Verhältnisse eng, aber ein gutes Wort bei den Pfarrern machte es möglich, den Kirchenraum einfach so zu unterteilen, daß während anderer Veranstaltungen der Altar verdeckt wurde. So einfach ist das. Übrigens waren auch die französischen Verantwortlichen in Genissiat von dem „Hohen Besuch“ so beeindruckt, daß Unregelmäßigkeiten fer- 
nerhin unterblieben. Der abgelöste Vertrauensmann aber, der nicht nur Leid und Not seiner Mitgefangenen, sondern auch einige dort wegen körperlicher Schwäche Verstorbene auf dem Gewissen hatte - dieser Mann war der erste und letzte, den ich bei seiner Rückkehr ins Dépôt filzen ließ. Dies tat die Lagerpolizei. Sie bestand aus vier Gefangenen. Es gehörte übrigens im Juni 1946 zu meinen ersten Amtshandlungen, deren Knüppel zu kassieren. Sie wurden nicht mehr gebraucht. Es ging ja auch so bestens. Der Ankömmling hatte mehrere Schweizer Uhren versteckt. Natürlich wußten wir, wo wir suchen mußten. Rasierpinsel, Schuhabsätze u.a. waren beliebte Verstecke. Nach wenigen Tagen wurde der Gefangene in ein Bergwerk versetzt.

A propo: Mort par cachexie. Diesen Begriff habe ich noch in Erinnerung. Ich übersetzte ihn damals mit "Tod durch körperlichen Verfall“. Auf gut deutsch waren solche Gefangene vor Entkräftung gestorben, also verhungert. Im Bereich des Dépôt de PG 142 liegen über dreihundert deutsche Soldaten unter der Erde. Ich habe alle ihre Dossiers gelesen, und weit überwiegend war mort par cachexie die Todesursache. Und fast alle waren sie vom Sommer 1944 bis Ende 1945 gestorben. Als ich im Sommer 1946 diese Akten in die Hände bekam, begann ich mit vielen Hinterbliebenen zu korrespondieren. Eine erschreckende Arbeit und eine große dazu. Inzwischen beschäftigte ich einen Sekretär mit klappriger Schreibmaschine. Ich muß daran erinnern, daß ich zu jener Zeit noch keine 25 Jahre alt war. Es bedurfte eines starken Herzens und großer seelischer Kraft, um hinterbliebenen Frauen, Müttern und Bräuten in dieser insgesamt so schwierigen Zeit alle Fragen zu beantworten, soweit das irgendwie noch ging.

Wie viele deutsche Soldaten sind in französischer Kriegsgefangenschaft gestorben? Im Frühjahr 1987 sah ich im ZDF in der Sendereihe „Damals“ ein Interview. $\mathrm{Zu}$ meiner Überraschung hörte ich aus dem Munde eines Sprechers des „Instituts für Zeitgeschichte“, daß es keine französischen Aufzeichnungen gibt. Warum? Das Dépôt mit der Nummer 142 kennt allein über dreihundert Tote. Man weiß laut Bericht der „Wissenschaftlichen Kommission der Bundesregierung zur Geschichte der deutschen Kriegsgefangenen des zweiten Weltkriegs", daß nach Kriegsende 1065000 deutsche Kriegsgefangene in französischer Hand waren. Die Franzosen haben offenbar penibel darüber Buch geführt, wer aus Gefangenschaft flüchtete und wer wieder eingefangen wurde. Auf den Kopf genau: 171029 brachen aus, 81507 erreichten die Heimat, 89522 Gefangene wurden wieder gefaßt. Aber die Zahl der Toten kennt man nicht, obwohl man doch hoffentlich über die Zahl der Entlassenen genaue Notizen gemacht hat. Im Bericht der „Wissenschaftlichen Kommission“ heißt es zu diesem Thema: „Die Erwartung, die Mortalität unter den Gefangenen im Bereich einer westlichen Gewahrsamsmacht mit genauen Zahlen belegen zu können, bleibt unerfüllt. Zum Verständnis trägt jedoch bei, daß unter 
den Verhältnissen in den ersten Monaten nach Kriegsende auch im Westen manches dunkel blieb, dunkel bleiben mußte. Das Chaos verdarb so manche gute Absicht, die sich auf dem Papier fürsorglich, menschlich und übereinstimmend mit dem Genfer Recht ausnahm."

„Dunkel bleiben mußte“ ..., ,auf dem Papier übereinstimmend mit dem Genfer Recht ..." Welch elegante Formulierungen! Es hat keinen Sinn, hier weiterzugrübeln; denn immerhin soll, so lese ich, die schreckliche Zahl von sechs Millionen ermordeten Juden wissenschaftlich gesichert sein. Dabei bin ich alles andere als ein „Aufrechner“. Es geht mir wirklich nur um Sachlichkeit, Wahrheit und Logik.

Meine im Juni übernommene Arbeit als Hauptvertrauensmann nahm mich sehr in Anspruch. Ich hatte wieder, wie einst bei den Panzerjägern, einen voll ausgefüllten Tag bis weit in die Nacht hinein und über Monate hinweg - dank der sonntäglichen Kommandofahrten - kein Wochenende. Die Verbindung zur Heimat war normalerweise auf einen Brief und eine Postkarte pro Monat beschränkt. Im Laufe der Zeit benützte ich aber stillschweigend auch normale Briefbogen und konnte so meine Nachrichten mehren. Jeder Brief drehte sich um die Frage nach der Heimkehr. Niemand konnte sie beantworten. Jeder von einem Gericht Verurteilte kennt sein Strafmaß. Bei guter Führung kann er damit rechnen, sogar früher entlassen zu werden. Für uns hingegen war der Tag der Freiheit nicht vorhersehbar. Es versteht sich, daß es im Laufe der Zeit immer schwieriger wurde, die Verbindung zu Irmgard allein über das geschriebene Wort aufrechtzuerhalten. Wie sehr uns die Frage nach der Zukunft hinter dem Stacheldraht quälte, mögen ein paar Beispiele aus der damaligen Korrespondenz erklären:

\section{August 1946:}

Unter den Klängen Beethovenscher Musik beginne ich heute mit einem zärtlichen Kuß für Dich meine Zeilen. Ich weiß nicht, Kind, wenn ich solche Musik höre, bin ich zu Hause, sitze auf dem Sofa und sehe nur die beleuchtete Skala des Rundfunkgerätes. Und Du sitzt dann neben mir, und ab und zu drücke ich Deine Hand, wenn mich eine hervorragende Stelle der Tonschöpfung ganz besonders packt. Es ist wahr, Kind. Unsere großen Musiker, Dichter und Denker geben mir so viel, daß mir das Niedrige, Gemeine und Dreckige nichts anhaben kann. Sie sind auch mit mein größter Halt in der schweren Zeit der Gefangenschaft.

Wir haben nun auch hier im Lager begonnen, kammermusikalische Feierstunden zu veranstalten. Geige, Flöte und Klavier stehen uns zur Verfügung. Eine Bratsche habe ich noch bei der YMCA bestellt. Ja, mein allerliebstes Kind. Am 21. August mache ich 500 Tage Gefangenschaft voll. Eine furchtbar lange Zeit und doch eigentlich nichts im Leben. Hoffen wir, daß ich nicht mehr allzulange von Dir weg bin. Diese Zeit 
kann uns beiden aber keinen Schaden antun, wenn Du mich so sehr und wahrhaft liebst wie ich Dich. Ich glaube an Dich, Kind, denn Du bist ein Stück von mir. Mehr kann ich Dir nicht sagen. [...]

\section{August 1946:}

[...] Außerdem habe ich heute ein Jubiläum zu feiern, von dem ich jedoch lieber verschont geblieben wäre. Fünfhundert Tage bin ich mit dem heutigen Tage hinter Stacheldraht. Ich darf nicht daran denken, wie schön diese Zeit bei Dir gewesen wäre, und ich darf auch nicht daran denken, wie schwer ich damals körperlich, seelisch und moralisch litt. Aber trotz allem Unglück und der furchtbarsten Enttäuschung vom 6. 2. 46 habe ich doch noch ein gütiges Schicksal gefunden, und wenn ich an Hunderttausende von Kameraden denke, dann will ich doch lieber schweigen. Meine Rechnung über 1 $1 \frac{1}{2}-2$ Jahre Gefangenschaft, die ich am 9.4.45 aufstellte, scheint doch so ziemlich aufzugehen.

Ich weiß, Kind; es ist viel, wenn ich von Dir verlange, auf mich zu warten, zumal der Tag des Wiedersehens noch unbestimmt ist. Ich glaube aber auch, daß Deine Liebe zu mir noch so groß ist, um die schwere Zeit des Alleinseins zu überbrücken.

Ich kann heute noch nicht sagen, was ich in Zukunft zu tun gedenke, da ich so vollkommen aus dem Alltag herausgerissen bin, daß mir jede Möglichkeit fehlt, hier einen vernünftigen Maßstab anzulegen. Du kannst aber überzeugt sein, Kind, daß ich nicht eher ruhen werde, bis unser beider Leben wieder lebenswert ist. Mein ganzes Sinnen und Trachten geht aber zunächst nur danach, recht bald für immer nach Hause zu kommen, und erst wenn ich bei Dir bin, ist es mir möglich, bei Dir und durch Dich so viel Kraft zu schöpfen, daß ich mit Erfolg an die Arbeit gehen und vorwärtskommen kann. [...]

\section{Dezember 1946:}

[...] In drei Tagen schreiben wir den 10.12. 1946. Damit jährt sich ein Tag zum dritten Male, seit welchem ich trotz Krieg, Not, Hunger, Elend, langer Trennung und großer Sehnsucht ruhig, zufrieden und glücklich bin. Dabei mögen die äußeren Umstände meiner gegenwärtigen Lebenslage so sehr auf mich eindringen, wie immer sie nur wollen. Ich vergesse nicht unsere erste Verabredung vor drei Jahren und nehme mir oft geistige Ferien. Ich kehre in jene Zeit zurück und fahre mit Dir in Urlaub. Niemand kann mir diese schönen Tage nehmen. Sie bilden einen großen Teil der Grundlage meiner Tatkraft als junger Mensch vor über 5000 Männern. Vielleicht sollte ich mir hier nicht so viele Sorgen machen, Kind; gewi $\beta$, Du hast recht. Aber, könnte ich denn anders vor mir selbst bestehen?

Wir wollen an Weihnachten und an Silvester unsere Gedanken noch enger verknüpfen als sonst und beide recht fest die Daumen halten, daß es 
1947 klappt. Wenn auch die Lage der amerikanischen Kriegsgefangenen in Frankreich noch nicht endgültig entschieden ist, so glaube ich doch, daß wir Hoffnung haben dürfen. Mein innigster Wunsch Tag für Tag und Woche für Woche ist nur der, daß ich Dich wieder so finden werde, wie ich Dich verlassen habe, daß Du stark bleibst und auf mich wartest. Niemand weiß besser als ich, wie schwer diese Zeit auf Dir lastet. [...]

Wieder stand der 14. Oktober ins Haus. An diesem Tage sollte ich nun ein Vierteljahrhundert vollenden. Was hatte das Schicksal in den letzten zwölf Monaten nicht alles für mich aufgehoben. Wie weit lag der Tag der Kartoffelklöße und der Zeltgemeinschaft unter Frankreichs südlicher heiBer Sonne zurück. Hier haben mich die Kameraden aus meiner nächsten Umgebung, weitgehend in den verschiedensten Stellen des Dépôts tätig, mit manchen Aufmerksamkeiten bedacht. Ihre schriftlichen Grüße waren durchwegs auf handbemaltem Papier ausgedrückt. Ich besitze diese Erinnerungsstücke, kleine Kunstwerke, heute noch. Um 6.30 Uhr spielte man ein Morgenständchen. Vier Musiker aus dem Lagerorchester (ein tragbares Harmonium, Posaune, Saxophon und Geige) ließen das Lied ,,Schier dreißig Jahre bist Du alt" und den Choral „Lobet den Herren" erklingen. Beides wurde auch bei anderen Geburtstagskindern vorgetragen. Es spielte dabei keine Rolle, daß keiner von den Beglückten gerade 30 Jahre alt wurde. Die Lagerzeitung griff noch einmal zu Feder und Tinte. Wie in alten Zeiten wurde von Hand geschrieben, diesmal eine Sondernummer mit „DNB“-Nachrichten, was nicht „Deutsches Nachrichtenbüro“, sondern „Doch nur Blödsinn“ hieß. Dieses Einzelexemplar, ein glänzendes Beweisstück für Humor hinter dem Stacheldraht, ist wohlverwahrt in meinen Händen.

Ich berichtete Irmgard von unseren Lageraktivitäten scheinbar so begeistert, daß sie aus meinem Brief vom 26. Oktober den Eindruck gewann, ich würde wohl gar nicht nach Hause wollen. Welch ein Trugschluß. Aber ich habe hier, wie schon vorher und später über Jahrzehnte hinweg im Berufsleben, stets mindestens $100 \%$ ige Leistung bringen wollen. Ich konnte gar nicht anders. Das machte mir Spaß, ja das brauchte ich. Entweder ich engagierte mich mit Begeisterung für eine Sache, oder ich ließ sie liegen. Und hier in Gefangenschaft spürte ich stark, wie sehr Eigeninitiative hilfreich sein konnte. An dieser Stelle meine ich sagen zu müssen, daß nach meinem Eindruck gar oft die Verhältnisse in Gefangenenlagern deshalb schlecht waren, weil die deutsche verantwortliche Führung versagte oder nur in die eigene Tasche wirtschaftete (Lager 404).

Nach all den Ereignissen und Eindrücken in der ersten Dezemberhälfte, Mord an zwei Kameraden und Beseitigung von Mißständen in Genissiat, rückte nun doch das Weihnachtsfest näher und näher. Nach $1940 / 1941 / 1942 / 1944 / 1945$ sollte dies also in sieben Jahren mein sechstes Weihnachten fern der Heimat sein. Wir hatten es in der Hand, die Tage so 
besinnlich und feierlich, aber auch so nahrhaft wie möglich zu gestalten. Dazu waren die richtige Organisation, der entsprechende Personaleinsatz und Geld nötig.

Letzteres hatten wir aus unserem Kantinengeschäft, dessen Überschuß ja ausschließlich für die Gemeinschaft verwendet wurde. Unser größter Einkauf war ein ganzes Schwein für das Weihnachtsessen. Unser Nürnberger Metzger Michael Herzog befaßte sich mit diesem schönen Stück Vieh in der Lagerküche, die übrigens auch jetzt noch reichlich primitiv eingerichtet war. Noch heute sehe ich auf einem Foto Stapel von gewöhnlichen Eimern, die man sonst zur Pferdetränke benützte. Sie haben bis zuletzt dazu gedient, das Essen auf die Zimmer zu verteilen.

Was wir zu Weihnachten auf die Beine brachten und wie wir das Fest erlebten, geht in konzentrierter Form aus meinem Brief an Irmgard vom 26. Dezember 1946 hervor:

„Meine allerliebste Irmgard!

Weihnachten liegt hinter uns. War ich auch fern von Dir, so verlief unser Fest im Lager doch so harmonisch, daß wir es nie vergessen werden. Am Nachmittag des 24. Dezember fand eine Weihnachtsfeier unter Mitwirkung unseres Kammertrios (Flöte, Violine und Klavier) und des Lagerchores statt. Unser Kapellmeister spielte als Weihnachtsgeschenk Max Bruchs Violinkonzert Nr. 1 g-moll. Während der Feier wurden auf den Stuben die Tische gedeckt. Jedes Zimmer hatte seinen geschmückten Weihnachtsbaum mit Kerzen. Jeder Mann im Lager und Lazarett bekam auf den weiß gedeckten Tisch 1 Weihnachtsstollen (über $1 \mathrm{~kg}$ ), 1 Dattelfruchtplatte, 1 amerikanische Konserve, 1 Lebkuchen, einige Äpfel und eine handgemalte Weihnachtskarte. Dazu kam die Spende des Roten Kreuzes: pro Mann 5 englische Zigaretten.

Das Essen war gestern und heute auch vortrefflich. Zweimal gab's Schweinebraten, am 24. Dezember Bratwurst mit Salat und einmal Goulasch. Unser Nürnberger Metzger Michael Herzog hat seine Sache gut gemacht und außerdem noch für jeden eine gute Blutwurst hergezaubert. $\mathrm{Zu}$ jeder Mahlzeit gab's Bohnenkaffee mit Milch. Wie Du siehst, hatte unser Magen auch Feiertag.

Gestern nachmittag war ein festliches Weihnachtskonzert angesetzt, und am Abend spielte unsere kleine Theatergruppe Theodor Körners „Nachtwächter", bearbeitet von Fritz Schrewe (Lagerzeitung). Es war ein großer Erfolg, alles war restlos begeistert.

Die Festgottesdienste wurden sehr feierlich untermalt durch das mitwirkende Trio und den Lagerchor, in dem ich auch mitsinge (II. Baß). Weithin sichtbar strahlt für alle ein großer Baum mit elektrischen Kerzen im Hof der Kaserne. Es war ein unvergeßliches Weihnachtsfest, doch fehlten uns allen unsere Lieben zu Hause. Nun bin ich froh, daß wir diese Tage hinter uns haben. Es hat mich viel Nerven gekostet. Ich 
bin froh, daß trotz der unheimlichen Schwierigkeiten alles bis auf die Minute geklappt hat. ..."

Die einen bedrückt, andere voller Hoffnung, manche vom Lagerkoller befallen, überwanden wir Silvester und den ersten Tag im neuen Jahr 1947. In der Gerüchteküche kochte es immer stärker. Die Parolen schwankten zwischen Entlassung im Frühjahr und ,spätestens Herbst“. Kein Wunder, daß unsere Nerven zum Zerreißen gespannt waren. Wir stürzten uns in die Arbeit. Der Thespis-Karren lief auf vollen Touren. Die Theatergruppe probte und spielte wie besessen. Kann sich einer vorstellen, was allein von unseren Kulissenmalern in dieser Zeit unter primitiven Voraussetzungen gezaubert wurde? Ihr Kulissenmaterial bestand aus zerlegten Rot-Kreuz-Kisten, Sperrholz u. ä. Es ist kaum zu glauben, was man daraus machen konnte. Leider geben meine mit nach Hause gebrachten Fotos in schwarz-weiß nicht den Eindruck wieder, den jeder Theaterbesucher damals hatte. Nach dem „Nachtwächter" von Theodor Körner wurden innerhalb weniger Monate auf die Beine, sprich Bühne, gebracht: ,Wer", Krimi von K. Hoffmann, ,Geheimnisvolle Ehe“" von Hans Fitz, „Oh, diese Frauen“. Im Nebenlager Vennes spielte man ,Was Du ererbt von Deinen Vätern“"von Franc Müller. Ja selbst in Genissiat stieg man inzwischen auf die Bretter, die die Welt bedeuteten. An Ostern gab man „Das Spiel im Schloß“" von Eduard Kobetzki.

Dabei zogen die Wochen ins Land. Am 25. Januar war es nun ein Jahr her, daß ich mit mehreren tausend Kameraden von den Amerikanern offiziell ,entlassen“" wurde. Damals wurden wir zu Transporteinheiten von jeweils ca. 1500 Mann eingeteilt. Wir trugen alle die schwarz gefärbte AmiUniform mit PW-Zeichen. Wir hatten alle unsere Unterschriften geleistet, u.a. auch auf einer Verdienstbescheinigung, wonach ich bei der amerikanischen Gewahrsamsmacht ein Guthaben von ca. 110 Dollar hatte; eine Summe, die ich mir im Arbeitseinsatz à conto verdient hatte. Ich habe ferner schriftlich bestätigt, daß ich nach den Vorschriften der Genfer Konvention behandelt wurde, soweit diese die Kriegsgefangenen betrifft.

Darin eingeschlossen war meine absolut unwahre Bestätigung, immer „über" dem Erdboden geschlafen zu haben. Das spielte für uns damals keine Rolle mehr. Nur noch heim wollten wir. Am 27. Januar 1947 schrieb ich einen längeren Brief als sonst an Irmgard. Ich mußte mir wieder einmal alles von der Seele reden. Ich schrieb u.a.:

Am 5. Februar sind es sechs Jahre, daß ich den grauen Rock anzog. Das siebente Jahr werde ich wohl nicht mehr vollenden. Zur Zeit steigt unser Stimmungsbarometer wieder einmal. Die Ami-Gefangenen haben wieder Aussicht auf ,baldige“ Entlassung. Doch ob es bis zum Oktober klappt, wissen die Götter. Ich hoffe es jedenfalls. Kannst Du noch so lange auf mich warten, Kind? Ich weiß, die Zeit der Trennung ist für Dich schwerer als für mich. Du stehst zu Hause im Leben des grauen 
Alltags, verkehrst in Gesellschaft, hast Freunde und Bekannte, denen Du Dich widmest. Geist und Empfinden werden so vielseitig bei Dir angeregt, daß die gedankliche Verbindung zu mir, einem Menschen hinter Stacheldraht, allmählich und ganz unbewußt verblaßt. - Ich würde mich unendlich freuen, wenn ich in diesem Falle nicht recht haben sollte. Umgekehrt ist es nämlich tatsächlich so, daß ich gegenüber allen Gefahren des Vergessenkönnens gefeit bin. Damit will ich nicht sagen, daß ich in der Vergangenheit lebe und in der Erinnerung glücklicher Stunden und Tage schwelge, diese als das Heil des Lebens betrachtend. Nein, das nicht. Aber meine Gedanken werden selbst durch noch so viele Arbeit und wenn ich hier in den angenehmsten Verhältnissen leben sollte, nicht von dem einen großen Ziel abgelenkt, in die Freiheit, nach Hause, zu Dir zurückkehren zu wollen. Damit bringe ich gleichzeitig zum Ausdruck, daß Dein Bild noch klar und deutlich vor mir steht, genau so, wie ich Dich vor zwei Jahren verlassen habe. Und nichts kann mich davon ablenken. Wäre es nicht so, dann suchte ich nur die Freiheit als solche, und diese fände ich auch hier in Frankreich. Sie wäre mir aber trotz materieller Vorteile unvollkommen, ich suche sie nicht und will sie nicht haben. Diese Art von Freiheit wäre nur eine reine Flucht vor dem so verhaßten Stacheldraht, ohne jeden tieferen Sinn. - Vielleicht verstehst Du mich nicht recht, Kind, und denkst:, Was sollen denn all diese Worte?' Gewiß, ich schreibe selten, weil ungern, über dieses Problem. Es ist mir an und für sich zu selbstverständlich, um große Worte darüber zu verlieren. Aber da ich sehr stark fühle, daß Du Dir täglich hundertmal die Frage vorlegst: ,Wie soll es weitergehen?" und ,Was bringt uns die Zukunft?', muß ich dies heute wieder einmal schreiben. Ich weiß wohl, was Dich alles bewegt, Kind, doch kann ich von hier aus nicht sagen, was ich später zu unserem Vorteil zu tun gedenke. Ich muß Dir erst wieder einmal in die Augen sehen, und Du mußt umgekehrt das gleiche getan haben; dann wirst Du wissen, was ich heute zum Ausdruck bringen wollte, und vieles wird ein anderes Gesicht bekommen, glaub mir das ..."

Und am 5. Februar 1947 konnte ich meinen Brief an Irmgard begreiflicherweise nur damit beginnen: „Heute vor sechs Jahren habe ich mich zur Ableistung meiner Wehrpflicht in der Großreuther Kaserne eingefunden. Damit sind sechs meiner schönsten Lebensjahre dahin. Morgen, am 6. Februar ist es ein Jahr her, daß ich an den französischen Staat ,verkauft" wurde.“ Und dann der Schluß: „Hoffentlich wird es bald amtlich, daß wir entlassen werden. Vielleicht noch in der ersten Jahreshälfte?? Man glaubt wahnsinnig zu werden, wenn man daran denkt, daß das alles bald ein Ende haben soll."

Und es wurden tatsächlich welche wahnsinnig. Gerade in diesen Tagen wurden zwei Kameraden als total verrückt in das Lazarett eingeliefert. Sie hatten völlig durchgedreht. 


\section{Frühjahr 1947: Die Entlassung}

Am 3. Februar schrieb ich meiner Mutter zur Vollendung ihres 55. Lebensjahres einen von Künstlerhand gerahmten Brief. An ihrem Geburtstag, dem 19. Februar, eröffnete mir der Kommandant, daß ich meinen Nachfolger wählen lassen und einarbeiten sollte. Welch ein erregendes Gefühl!! Ich wagte nicht daran zu denken, daß es diesmal ernst würde. Oder sollte wieder etwas dazwischenkommen wie 15 Monate vorher? Nein. Diesmal wurde es Wirklichkeit. Mein Nachfolger wurde gewählt und von der Kommandantur akzeptiert. Ein Transport wurde zusammengestellt, der sich am 17. April 1947 abends auf den Weg nach Deụtschland machte. Unser Lagerschreiner überraschte mich noch mit einem von ihm fabrizierten Holzkoffer, mit dem ich reichlich vornehm die Heimreise antrat. Ich kann es nicht verdrängen, daß mir am letzten Tag im Dépôt der Abschied von all den Kameraden trotz der Aussicht auf die lang ersehnte Freiheit schwerfiel. Mehrfach war ich dem Weinen nahe, als ich alten Mitstreitern die Hand drückte, ihnen für viel Enthusiasmus und Fleiß dankte und baldige Heimkehr wünschte. Ich kam mir fast wie ein Abtrünniger vor, und doch hatte ich zu meiner Entlassung überhaupt nichts beigetragen. Im Zuge der jetzt erst beginnenden normalen Rückführung ging es nicht mehr um den Krankenstand, sondern um Merkmale, die vom Kommandanten beeinflußt wurden. Wer sich verdient machte, war bei den ersten. Das war für den Kommandanten Anlaß, mich auf die Liste zu setzen.

Unter dem Datum 17. April 1947 wurde vom Kommandanten das folgende bestätigt:

„Der Kapitän de la Rupelle, Kommandant des Kriegsgefangenenlagers Nr. 142 in Bourg, bescheinigt, daß der obstgenannte Kriegsgefangene Hans Jonitz nach Deutschland entlassen wird. Ehrenvoll und pflichterfüllt hat er dem Lager, dem er seit dem 27.2.1946 angehörte, immer gute Dienste geleistet. Er war während 11 Monaten als Hauptvertrauensmann tätig.

Von aufrechtem Charakter, mit außerordentlicher Gewissenhaftigkeit seiner Aufgabe ergeben, ist er täglich ein getreuer Vertreter seiner Kameraden gegenüber der französischen Lagerverwaltung gewesen.

Er hat sich der physischen und moralischen Leiden seiner Kameraden angenommen, und durch seinen Einfluß, den er auf diese ausübte, erreichte er im Lager eine gute Disziplin, eine tadellose Haltung und vorbildliche Hygiene.

Sein Scheiden wird sowohl von seinen Kameraden als auch von dem französischen Lagerkommandanten sehr bedauert."

Ich erinnere mich der Abschiedsszene auf dem Bahnhof von Bourg. Ich stand im Kreise französischer Offiziere, darunter unser Kommandant, Comte de la Rupelle, und Monsieur Filliettaz aus Lyon. 
Mit letzterem vereinbarte ich noch, nach Rückkehr einen Bericht über die Geschehnisse rund um den Transport einschließlich der Entlassung abzugeben. Und als ich den Waggon bestieg, gab mir Comte de la Rupelle zum ersten Male persönlich die Hand. In diesem Augenblick rechnete er mich zu den Gleichberechtigten. Einem Gefangenen gibt man keine Hand. Wie anders waren da die Amis im Lager 416 (nicht 404!).

Der Transport brach in Richtung Tuttlingen auf. In Kehl überfuhren wir den Rhein und erreichten damit deutschen Boden. Als der Zug dort für kurze Zeit anhielt, konnte ich nicht mehr an mir halten. Ich stieg aus, mit Tränen in den Augen, kniete nieder und küßte die deutsche Erde. Ich war wieder in der Heimat, in meinem Vaterland. Und unvorstellbare Glücksgefühle überströmten mich, ja uns alle.

In der Nacht zum 19. April trafen wir in Tuttlingen ein. Im Morgengrauen wurde entladen. Ich war Transportführer und meldete den Zug bei der dortigen Lagerleitung an. Man schleuste uns ins Lager, und wieder wurden Personalien aufgenommen. Diesmal ging es aber um das Certificat de Démobilisation, den Entlassungsschein. Und wieder wurde gefilzt, von Franzosen und Deutschen. Es war geradezu unglaublich. Gefangene, die vor Tagen noch ein Paar Schuhe gefaßt hatten, bekamen diese wieder abgenommen und gegen schlechtere getauscht. Völlig willkürlich wurde geplündert. Bezeichnenderweise machten sie bei mir als dem Transportführer keinerlei Anstalten. Gegen $11 \mathrm{Uhr}$ mittags traten wir in Marschordnung auf der Lagerstraße an, wohlversehen mit den Entlassungspapieren. Als der Schlagbaum geöffnet wurde, marschierten Hunderte von ehemaligen Landsern, wie sie es in Jahren nicht anders gekannt hatten, in die Freiheit und zum Bahnhof Tuttlingen. Bis auf einen. Der hieß Hans Jonitz. Nur ein paar Meter hinter dem Schlagbaum setzte ich mich auf meinen Holzkoffer, entnahm meiner Brusttasche die einzige vorhandene $\mathrm{Zi}$ garre, zündete diese an und rauchte sie in aller Ruhe. Ich war wieder Individualist geworden.

Daraufhin ging ich in die nächstbeste Tuttlinger Wirtschaft und kaufte mir eine Halbe Dünnbier. Etwas anderes gab es nicht. Erst dann machte ich mich auf den Weg zum Bahnhof, faßte beim Roten Kreuz meine Marschverpflegung und nützte die nächste Zugverbindung nach Stuttgart. Württembergs Metropole lag auf dem Weg nach Nürnberg. Ich wollte noch bei Familie Hiller Besuch machen und mich nach Hauptmann a. D. Hiller erkundigen. Die Eltern fand ich vor. Der Sohn studierte inzwischen in Frankfurt Betriebswirtschaft, war also einigermaßen genesen aus den USA nach Hause gekommen.

Am 21. April 1947 traf ich in Nürnberg ein. Endlich, endlich. Die Freude auf allen Seiten war überschwenglich. Die Arbeit im Frieden, der Aufbau einer Existenz konnte beginnen. Zuvor wollte ich aber noch ein Versprechen einlösen und den Bericht an das Comité International de la 
Croix Rouge in Lyon schreiben. Bereits am 28. April gab ich eine ausführliche Darstellung der Situation im Entlassungslager Tuttlingen:

„Sehr geehrter Herr Filliettaz, unserem gemeinsamen Wunsch entsprechend möchte ich Ihnen, wie am Bahnhof von Bourg versprochen, einen kurzen Bericht über meine Eindrücke im Entlassungslager Tuttlingen geben.

Der Transport der VIII. Région militaire (1408 P.G.) kam am 19. April 1947 morgens um 3.30 Uhr in Tuttlingen an und wurde um 6.30 Uhr an die Rampe, unmittelbar am Eingang des Lagers, vorgezogen. Die Dekken und Wasserkannen wurden abgegeben und in einem Waggon gesammelt.

Gegen 7.00 Uhr marschierte der Transport in Gruppen zu 100 Mann ins Lager. Eine Gepäck-Kontrolle fand nicht statt, jedoch wurden wir einzeln, Mann für Mann, in ein Camp geschleust und dabei schätzungsweise 100 Mann zurückgehalten. Wie ich feststellen konnte, wurden diesen Leuten, davon einigen mir bekannten Employés des Dépôt de P.G. 142, Schuhe, Hosen, ja sogar selbst angefertigte Mützen abgenommen und gegen alte, zum Teil fast unbrauchbare Kleidungsstücke getauscht. Den P.G.s wurden dabei Schuhe und Hosen abgenommen, die sie teilweise erst vor wenigen Tagen und Wochen in den Dépôts empfangen hatten. Sie können sich denken, daß diese Maßnahme unter den P.G.s eine begreifliche Erregung hervorgerufen hat. Es war den P.G.s in ihren früheren Dépôts weder bekanntgemacht worden, welche Kleidungsstücke (amerikanischer, französischer oder deutscher Herkunft) zu tragen verboten seien, noch konnte irgendein Prinzip festgestellt werden, nach welchem in Tuttlingen der Umtausch der Bekleidung geschah. Der Umtausch erfolgte wahllos und immer sehr zum Nachteil der P.G.s. Ich habe mit Kameraden gesprochen, die mit zerrissenen Schuhen die Heimreise antreten mußten und zu Hause als total Bombengeschädigte kein Schuhwerk mehr besitzen.

Um diese Zustände abzustellen, wäre eine Intervention des Comité International de la Croix Rouge unbedingt erforderlich. Vielleicht wäre es auch angebracht, nachdem nun laufend Transporte nach Tuttlingen und Bretzenheim kommen werden, jeweils einen ständigen Delegierten des Roten Kreuzes nach dort zu senden.

Im übrigen geht die Ausstellung der Entlassungspapiere und Fahrkarten sehr schnell vonstatten. Der gesamte Transport wurde im Laufe des Morgens des 19. 4. abgefertigt. Ich selbst verließ um 11 Uhr das Lager, nachdem uns noch die nächsten Zugverbindungen nach den verschiedenen Richtungen bekanntgegeben wurden. Es war gewährleistet, daß jeder Entlassene noch am gleichen Tage Tuttlingen verlassen konnte.

Die Fahrt von Bourg nach Tuttlingen selbst verlief ohne Zwischenfälle. Es wäre jedoch angebracht, das Offenhalten der Waggontüren während der Fahrt zu gestatten. Die Marschverpflegung war ausreichend. Am 
19.4. wurde der Transport durch die Betreuungsstelle des Bahnhofs Tuttlingen verpflegt. Außerdem kann sich der entlassene P.G. während seiner Fahrt durch Deutschland an jede Betreuungsstelle des Roten Kreuzes wenden.

Ich würde mich freuen, wenn Ihnen der obige kurze Abriß die Möglichkeit geben würde, die gegenwärtige Situation im Lager Tuttlingen zu beurteilen, und wäre Ihnen für den Empfang dieses Berichtes sehr dankbar.

Abschließend kann ich Ihnen noch mitteilen, daß ich am 21.4. 47 wohlbehalten in meinem furchtbar zerstörten Heimatort angekommen bin. Ich bin glücklich, in diesem Trümmerfeld noch ein Heim zu besitzen. Ich danke Ihnen nochmals für Ihre Aktivität, welche Sie während meiner Tätigkeit als Hauptvertrauensmann des Dépôt de P.G. 142 für uns alle an den Tag gelegt haben, und bleibe mit den besten Wünschen Ihr sehr ergebener ..."

Monsieur Filliettaz antwortete bereits am 20. Mai. Die deutsche Übersetzung lautet:

„Ich danke Ihnen aufrichtig für Ihren Brief vom 28. April, welchen ich am 13. Mai erhielt. Eine Kopie Ihres Berichtes übersende ich an unsere Delegation nach Paris, welche ich schon durch Telefon über die Situation bei der Ankunft der Entlassungszüge in Tuttlingen informierte. Von seiner Seite aus hat der Regionaldirektor ebenfalls die Generaldirektion für Kriegsgefangene unterrichtet. Man darf deshalb hoffen, daß diese Zustände sich sehr bald ändern werden. Im übrigen wird eine Delegation des C.I.C.R. sehr wahrscheinlich an Ort und Stelle der Ankunft der meisten Züge beiwohnen.

Ihre Kameraden werden Ihnen sehr dankbar sein, daß Sie sich noch nach Ihrem Abschied für sie verwendeten. Persönlich danke ich Ihnen noch einmal für Ihren Brief und will hoffen, daß Sie trotz der ernsten Zerstörungen, welche Ihre Stadt erlitt, sehr schnell in Ihr freies Leben zurückfinden ..."

Dieser Brief vom 20. Mai war sehr lange auf dem Wege nach Nürnberg, weshalb ich am 30. Mai reklamierte. Beide Schreiben kreuzten sich. Aus dem weiteren Brief des CICR in Lyon, von Monsieur Filliettaz am 10. Juni geschrieben, ist für den Entlassungsvorgang nur noch der erste Absatz wichtig. Er lautet übersetzt: „Ihr Schreiben vom 30. Mai habe ich bestens dankend erhalten. Ich bin überrascht, daß meine Antwort auf Ihren Bericht nicht in Ihren Händen ist. Die Auskünfte, welche Sie mir gegeben haben, waren sehr interessant, und ich habe sie weitergegeben an unser Comité in Genf und an unsere Hauptdelegation in Paris. Als Folge unserer Demarche findet in den Entlassungslagern der französischen Besatzungszone keinerlei Filzung und Wegnahme von Bekleidungsstücken mehr statt ..."

Dies war mein letztes Werk im Dienste meiner mitgefangenen Kamera- 
den. Die regulären Entlassungen dauerten noch bis Ende 1948. Meine Demarche gegen die Ausplünderung von Kriegsgefangenen unmittelbar vor dem Schritt in die Freiheit hat also noch vielen Tausenden geholfen.

Es wird mir vielleicht niemand glauben, aber am Tage nach meiner Heimkehr ging ich bereits neugierig zur MAN, um erst einmal alte Kollegen zu besuchen. Der Zufall wollte es: Schon vor der Hauptverwaltung beim großen Einfahrtstor kam mir mein Chef entgegen, Herr Prokurist Merkel. Er sagte nur in seiner trockenen, humorvollen Art: ,So, sind Sie auch wieder da? Sie können gleich anfangen." Tatsächlich war die Position des Abteilungs-Korrespondenten in der Abteilung für Lufttechnische Anlagen nur interimistisch besetzt.

Ich erledigte meine polizeiliche Anmeldung. Daraufhin wurde mir vom Wohnungsamt der Stadt Nürnberg eine Unbedenklichkeitsbescheinigung ausgestellt. Demnach, so hieß es, „,können auf Dauer Lebensmittelkarten ausgehändigt werden". Am 30. April bekam ich meine erste Zuteilung. Ich war damit nun auch ernährungs- und versorgungstechnisch in die Volksgemeinschaft aufgenommen. An meinem Entlassungstag, dem 19. April 1947, begann die 101. Zuteilungsperiode. Vierzig Jahre später konnte ich in der Süddeutschen Zeitung in der täglichen ,,Rückblick“-Spalte die der Bevölkerung seinerzeit zustehenden Rationen entnehmen:

„Am 19. April 1947 wurden die Rationen für die 101. Lebensmittelperiode bekanntgegeben. Die der westdeutschen Bevölkerung in den nächsten vier Wochen zustehenden Nahrungsmittel waren noch geringer als in der zu Ende gehenden 100. Zuteilungsperiode. Die Ernährungslage war so schlecht, daß die auf die Lebensmittelkarten aufgedruckten Mengenangaben nicht eingehalten werden konnten. Den Verbrauchern wurde mitgeteilt, daß es statt 10000 Gramm Brot nur 4000 Gramm, statt 200 Gramm Fett nur 150 Gramm und statt 1300 Gramm Nährmittel nur 600 Gramm gab. Lediglich die angegebene Menge von $600 \mathrm{Gramm}$ Fleisch wurde voll ausgegeben. In München stellte ein Geschäft zur Demonstration für die Ernährungskommission in einem Schaufenster die Tagesration eines Normalverbrauchers aus: 21,4 Gramm Fleisch, 7,1 Gramm Fett, 2,2 Gramm Käse, 214 Gramm Brot, 21,4 Gramm Nährmittel, 17,8 Gramm Zucker und einen Zehntelliter Milch.“

Die wiedergewonnene Freiheit war also mit mehr Hunger verbunden; denn zuletzt lebten wir in Kriegsgefangenschaft dank eigener Initiative recht ordentlich. Aber diese kostbare Freiheit war wichtiger als alles andere. Es war jetzt an der Zeit, mit fast 26 Jahren eine Existenz aufzubauen. Mit Irmgard war ich glücklich. Wir wollten unseren Lebensweg gemeinsam fortsetzen. Das setzte einen beruflichen Hintergrund voraus. Wie oft hatte ich mich hinter dem Stacheldraht danach gesehnt, endlich wieder in eigener Sache aktiv tätig werden zu können. Nun nahm ich am 5. Mai offiziell Kontakt zur MAN auf. Nach einem Wiedereinstellungsgespräch wurde mir mit Brief vom 30. Mai die Wiederbeschäftigung bestätigt. Als 
zweiter Abteilungs-Korrespondent war ich 1940 eingerückt, als erster Abteilungs-Korrespondent sollte ich jetzt beginnen dürfen. Der bisherige Amtsinhaber war noch nicht ,entbräunt", wie die Entnazifizierung damals im Volksmund hieß. Diese sollte noch über ein Jahr auf sich warten lassen. Ich selbst wurde am 20. Mai von der Spruchkammer als „Nicht betroffen" eingestuft. Der Wiederbeginn an alter Stelle nach fast sieben Jahren, am 1. Juni 1947, verlief problemlos. Indessen riß mich die Bezahlung für mein Wirken nicht vom Stuhl. Hatte man mir für die Zeit vom 2. Januar bis 4. Februar 1941, für jene Wochen zwischen Arbeitsdienst und Einberufung zur Wehrmacht am 5. Februar 1941 noch ein Bruttogehalt von RM 200,- bei damals 48 Wochenarbeitsstunden zugestanden, so galt ab 1. Juni 1947 der gleiche Betrag, obwohl ich die Arbeit meines damaligen Chefs ausübte. Aber nicht nur das. Wie viele andere Firmen arbeitete auch die MAN seinerzeit langfristig kurz. Für die volle Auslastung der Produktion war nicht genug Material vorhanden. Kurzarbeit hieß damals 40 Stunden/Woche. Dieser Lösung waren auch sämtliche Angestellten unterworfen, auch wenn diese mehr als ausgelastet waren. So schrumpften die RM 200,- auf RM 166,87 zusammen. Als Netto-Entgelt lagen nur noch RM 137,80 in der Tüte. Und das waren die seinerzeitigen Abzüge:

\begin{tabular}{ll} 
Lohnsteuer & RM 14,-- \\
Kirchensteuer & RM -,56 \\
Sozialversicherung & RM 14,51 \\
\cline { 2 - 2 } & RM 29,07
\end{tabular}

Wie mein Geburtsjahr 1921 war auch das Jahr meiner Wiedergeburt 1947 ein sehr heißes, und auch der 1947er Weinjahrgang zählt zu den AuBergewöhnlichen. Wir waren oft mit den Fahrrädern unterwegs. Wo immer möglich, versuchte man etwas zusätzliche Nahrung zu erreichen. Im Juni fuhren wir ,,in die Kirschen“. Kartoffeln konnten wir aus Altenthann mit nach Hause nehmen, wo ein Kamerad aus der Kriegsgefangenschaft eine kleine Landwirtschaft betrieb. Abend für Abend verbrachte ich, von wenigen Ausnahmen abgesehen, in der Wohnung von Irmgard, deren Vater seinerzeit bei der Nürnberger Häuteverwertung Schwerarbeit leisten mußte. Ehemals gelernter Metzger und dann ein kleiner Beamter beim Städtischen Schlacht- und Viehhof Nürnberg, wurde er als Parteigenosse 1945 entlassen. Etwa 1949 schlug ihm der ihm persönlich gut bekannte damalige Oberbürgermeister vor, der SPD beizutreten. Er könne sich dann für seine baldige Wiederverwendung einsetzen. Mein Schwiegervater verzichtete. Es genügte ihm, einmal eines Vorteils wegen - er wollte Beamter werden - bei einer Partei gewesen zu sein. So mußte er bis 1950 auf die Wiedereinstellung warten.

Das Wichtigste der Arbeit in der Häuteverwertung waren für uns die Mitbringsel in Form von Ochsenschwänzchen. Das waren die letzten End- 
stücke, nachdem der normale Ochsenschwanz verarbeitet war. Mit viel Arbeitsaufwand wurden die Schwänzchen enthaart und Knorpel für Knorpel mit dem Messer ausgeschabt. Das Ergebnis war immerhin eine wohlschmeckende Sülze. Wir konnten uns auch nicht beklagen, zu wenig Erbsen zu bekommen. Noch immer gab es Reste aus jenem Erbsensack, den die SS bei ihrem eiligen Rückzug aus der Sparkassen-Zweigstelle 7 im April 1945 zurückließ. Mais- und Grieß-Auflauf standen auch mehr als oft auf dem Speiseplan. Hochwertige Nahrung wie Butter oder Eier waren zu erhalten, wenn man ,,kompensieren“ konnte. Ein Zauberwort jener Tage. Es traf sich gut, daß Irmgard im Büro einer Lederwaren-Großhandlung angestellt war, wo sie gelegentlich ein Paar Schuhsohlen als Tauschmittel erhielt.

Ich sehe noch meine Mutter heulend in der Küche stehen, als sie eines Tages nach mehr als fünf Stunden langem Anstehen bei unserem Gemüsehändler mit nichts als ein paar Kohlrüben nach Hause zurückkehrte. Das war dann unser Essen vom Tage. Wer, wie meine Familie, nur in der Großstadt zu Hause war und keinerlei Beziehungen zur Landwirtschaft hatte, war arm dran. Irmgards Mutter hingegen hatte, welch ein Vorteil, zwei Schwestern und andere Verwandte in der Schweiz. Im Spätsommer 1947 reisten Irmgard und ich per Eisenbahn mit einer besonderen Dienstreisegenehmigung, beantragt durch MAN, in die französische Besatzungszone nach Friedrichshafen zur dortigen Bodensee-Messe. Wir waren Holzklasse gefahren, die Fenster teilweise noch mit Brettern vernagelt. Um so krasser war der Unterschied, als aus Richtung Schweiz ein schneeweißer Bodensee-Dampfer mit Schweizer Flagge einlief. Die dort ausstiegen, kamen für uns aus einer anderen Welt. Der Unterschied zu uns armseligen Deutschen war schon äußerlich eklatant. Wir hatten uns viel zu erzählen und fuhren am späten Nachmittag, reich beschenkt, nach Nürnberg. Unser Reichtum war nicht ungefährlich, denn die Franzosen kontrollierten in den Zügen beim Verlassen ihrer Zone.

Schweizer Zigaretten und Schokolade versteckte Irmgard hinter dem Gummisaum ihres Schlüpfers. Das heutige „Darunter" unserer Damenwelt wäre da völlig ungeeignet gewesen. Leider kam Irmgard krank nach Hause. Eine schwere Eileiterentzündung zwang sie ins Bett. So verlief unsere lang geplante Verlobung anders als erwartet. Wir beließen es beim Datum meines Geburtstages. Am 14. Oktober 1947 lag die Verlobte im Bett und der Bräutigam saß auf einem Stuhl neben der Bettkante. Für ein rauschendes Fest hatten ohnedies alle Mittel gefehlt. Meine Mutter zauberte eine kleine Buttercreme-Torte. Das war ein so eindrucksvolles Ereignis, daß wir es bis heute nicht vergaßen. 


\section{Anmerkungen}

' Vgl. Paul Carell/Günter Böddeker, Die Gefangenen. Leben und Überleben deutscher Soldaten hinter Stacheldraht, Frankfurt a. M. 1980, S. 178.

${ }^{2}$ P.G. bedeutet Prison de Guerre (Kriegsgefangener) und ist nicht mit dem nationalsozialistischen PG (Parteigenosse) zu verwechseln.

${ }^{3}$ Um die Versorgung von verwundeten Soldaten im Feld zu verbessern, wurde am 22. August 1864 die erste Genfer Konvention unterzeichnet; 1906 und 1929 wurde sie erweitert, 1899 und 1907 durch die Haager Konventionen auf den Seekrieg ausgedehnt. Am 12. August 1949 schlossen 57 Staaten auf Einladung des Roten Kreuzes vier Genfer Konventionen zum Schutz der Kriegsopfer ab. In der dritten ist die Behandlung der Kriegsgefangenen geregelt.

${ }^{4}$ Um die Jahreswende 1948/49 trafen sich in Hamburg erstmals ehemalige Angehörige der Waffen-SS, um wenig später die „Hilfsgemeinschaft auf Gegenseitigkeit" (HIAG) ins Leben zu rufen. Ihre Mitglieder hatten zunächst die Absicht, den für ihre Gruppe besonders schwierigen Anschluß an eine normale Entwicklung nach dem Krieg zu unterstützen, fielen aber durch rechtsextremistische Äußerungen und eine Verherrlichung ihrer SS-Zeit auf. 1979 stufte sie der Verfassungsschutz-Bericht als „rechtsextremistische Vereinigung" ein, was der Bundesinnenminister im Sommer 1983 allerdings vorerst wieder aufhob.

${ }^{5}$ Die Young Men's Christian Association, eine weltweite Gemeinschaft junger Männer, sah ihre Hauptaufgabe während und nach dem Zweiten Weltkrieg in der Hilfe für verschleppte Personen und Flüchtlinge. Generell gilt ihr als wichtigstes Ziel, die religiöse, soziale, geistige und materielle Entwicklung ihrer Mitglieder zu pflegen sowie den Ausbau der Beziehungen zwischen Nationen, Rassen und sozialen Gruppen zu fördern.

${ }^{6}$ Umerziehungspolitik ist der Sammelbegriff für alle Vorhaben der Alliierten nach dem Zweiten Weltkrieg, die nationalsozialistische Gleichschaltung des kulturellen und politischen Lebens der Deutschen rückgängig zu machen und die im Potsdamer Abkommen festgelegte ,endgültige Umgestaltung des politischen Lebens auf demokratischer Grundlage" im Hinblick auf die friedliche Mitarbeit Deutschlands am internationalen Leben zu bewirken. Die Umerziehung sollte in sämtlichen Alters- und Gesellschaftsschichten greifen. So sollte das Bildungswesen durch eine Schul- und Hochschulreform, die Beschlagnahmung von nationalsozialistischen Schulbüchern und eine Entnazifizierung der Lehrerschaft demokratisiert werden und besonders die Jugendlichen ansprechen. Die Pressepolitik - anfänglich waren alle publizistischen Aktivitäten untersagt, dann gab die Militärregierung Zeitungen heraus, und schließlich wurde demokratisch ausgerichteten deutschen Publikationen die Lizenz erteilt - zielte auf die Erwachsenen. Briten und Franzosen richteten ihre „Reeducation-Politik“ nach dem Beispiel der Amerikaner aus, die Sowjets bemühten sich, damit den gesellschaftlichen Umwandlungsprozeß in der SBZ zu beschleunigen. 